\title{
A fresh look at Cladarosymblema narrienense, a tetrapodomorph fish (Sarcopterygii: Megalichthyidae) from the Carboniferous of Australia, illuminated via X-ray tomography
}

\author{
Alice M Clement ${ }^{\text {Corresp., } 1}{ }^{,}$Richard Cloutier ${ }^{2}$, Jing Lu ${ }^{3,4}$, Egon Perilli $^{1}$, Anton Maksimenko ${ }^{5}$, John Long ${ }^{1}$ \\ ${ }^{1}$ College of Science and Engineering, Flinders University of South Australia, Adelaide, South Australia, Australia \\ 2 Département de Biologie, Chimie et Géographie, University of Québec at Rimouski, Rimouski, Quebec, Canada \\ 3 Key Laboratory of Vertebrate Evolution and Human Origins of Chinese Academy of Sciences, Institute of Vertebrate Paleontology and Paleoanthropology, \\ Beijing, China \\ ${ }^{4}$ CAS Center for Excellence in Life and Paleoenvironment, Beijing, China \\ 5 Australian Synchrotron, Australian Nuclear Science and Technology Organisation, Melbourne, Victoria, Australia \\ Corresponding Author: Alice M Clement \\ Email address: alice.clement@flinders.edu.au
}

Background. The megalichthyids are one of several clades of extinct tetrapodomorph fish that lived throughout the Devonian - Permian periods. They are advanced "osteolepidid-grade" fishes that lived in freshwater swamp and lake environments, with some taxa growing to very large sizes. They bear cosmine-covered bones and a large premaxillary tusk that lies lingually to a row of small teeth. Diagnosis of the family remains controversial with various authors revising it several times in recent works. There are fewer than 10 genera known globally, and only one member definitively identified from Gondwana. Cladarosymblema narrienense Fox et al. 1995 was described from the Lower Carboniferous Raymond Formation in Queensland, Australia, on the basis of several well-preserved specimens. Despite this detailed work, several aspects of its anatomy remain undescribed.

Methods. Two especially well-preserved 3D fossils of Cladarosymblema narrienense, including the holotype specimen, are scanned using synchrotron or micro-computed tomography ( $\mu \mathrm{CT})$, and 3D modelled using specialist segmentation and visualisation software. New anatomical detail, in particular internal anatomy, is revealed for the first time in this taxon. A novel phylogenetic matrix, adapted from other recent work on tetrapodomorphs, is used to clarify the interrelationships of the megalichthyids and confirm the phylogenetic position $C$. narrienense.

Results. Never before seen morphological details of the palate, hyoid arch, basibranchial skeleton, pectoral girdle and axial skeleton are revealed and described. Several additional features are confirmed or updated from the original description. Moreover, the first full, virtual cranial endocast of any tetrapodomorph fish is presented and described, giving insight into the early neural adaptations in this group. Phylogenetic analysis confirms the monophyly of the Megalichthyidae with seven genera included (Askerichthys, Cladarosymblema, Ectosteorhachis, Mahalalepis, Megalichthys, Palatinichthys, and Sengoerichthys). The position of the megalichthyids as sister group to canowindrids, crownward of "osteolepidids" (e.g. Osteolepis and Gogonasus), but below "tristichopterids" such as Eusthenopteron is confirmed, but our findings suggest further work is required to resolve megalichthyid interrelationships. 


\section{A fresh look at Cladarosymblema narrienense, a}

2 tetrapodomorph fish (Sarcopterygii: Megalichthyidae) from

3 the Carboniferous of Australia, illuminated via X-ray

4 tomography

5

Alice M. Clement ${ }^{1 *}$, Richard Cloutier ${ }^{2}$, Jing Lu ${ }^{3,4}$, Egon Perilli ${ }^{1}$, Anton Maksimenko ${ }^{5}$ \& John A. Long ${ }^{1}$

${ }^{1}$ College of Science \& Engineering, Flinders University, Adelaide, AUSTRALIA

2 Université du Québec à Rimouski, Rimouski, Quebec, CANADA

${ }^{3}$ Key Laboratory of Vertebrate Evolution and Human Origins of Chinese Academy of Sciences, Institute of Vertebrate Paleontology and Paleoanthropology, Chinese Academy of Sciences, Beijing, CHINA

${ }^{4}$ CAS Center for Excellence in Life and Paleoenvironment, Beijing, CHINA

${ }^{5}$ Australian Synchrotron, Australian Nuclear Science and Technology Organisation, Melbourne, AUSTRALIA

Corresponding Author: Alice M. Clement ${ }^{1^{*}}$

Flinders University, Sturt Road, Bedford Park, Adelaide, 5042, Australia.

Email: alice.clement@flinders.edu.au

\section{ABSTRACT}

Background. The megalichthyids are one of several clades of extinct tetrapodomorph fish that lived throughout the Devonian - Permian periods. They are advanced "osteolepidid-grade" fishes that lived in freshwater swamp and lake environments, with some taxa growing to very large sizes. They bear cosmine-covered bones and a large premaxillary tusk that lies lingually to a row of small teeth. Diagnosis of the family remains controversial with various authors revising it several times in recent works. There are fewer than 10 genera known globally, and only one member definitively identified from Gondwana. Cladarosymblema narrienense Fox et al. 1995 was described from the Lower Carboniferous Raymond Formation in Queensland, Australia, on the basis of several well-preserved specimens. Despite this detailed work, several aspects of its anatomy remain undescribed.

Methods. Two especially well-preserved 3D fossils of Cladarosymblema narrienense, including the holotype specimen, are scanned using synchrotron or micro-computed tomography $(\mu \mathrm{CT})$, and 3D 
modelled using specialist segmentation and visualisation software. New anatomical detail, in particular internal anatomy, is revealed for the first time in this taxon. A novel phylogenetic matrix, adapted from other recent work on tetrapodomorphs, is used to clarify the interrelationships of the megalichthyids and confirm the phylogenetic position $C$. narrienense.

Results. Never before seen morphological details of the palate, hyoid arch, basibranchial skeleton, pectoral girdle and axial skeleton are revealed and described. Several additional features are confirmed or updated from the original description. Moreover, the first full, virtual cranial endocast of any tetrapodomorph fish is presented and described, giving insight into the early neural adaptations in this group. Phylogenetic analysis confirms the monophyly of the Megalichthyidae with seven genera included (Askerichthys, Cladarosymblema, Ectosteorhachis, Mahalalepis, Megalichthys, Palatinichthys, and Sengoerichthys). The position of the megalichthyids as sister group to canowindrids, crownward of "osteolepidids" (e.g. Osteolepis and Gogonasus), but below "tristichopterids" such as Eusthenopteron is confirmed, but our findings suggest further work is required to resolve megalichthyid interrelationships.

\section{INTRODUCTION}

Megalichthyids are an extinct clade of sarcopterygian (lobe-finned) tetrapodomorph fishes known from predominantly freshwater deposits in the Palaeozoic. They appeared in the Mid-Late Devonian, and were one of the few sarcopterygian groups that survived the end-Devonian extinctions, persisting up until the Lower Permian (Witzmann \& Schoch 2012). They fall within an "osteolepidid-grade" in most phylogenetic analyses of stem-tetrapod interrelationships (Ahlberg \& Johanson 1998; Cloutier et al. 2020; Johanson 2004; Johanson \& Ahlberg 2001; Lu et al. 2012; Zhu \& Ahlberg 2004; Zhu et al. 2017). They are typically recovered most closely related to the East Gondwanan endemic group the Canowindridae (Beelarongia, Koharalepis, Canowindra), usually crownward of rhizodonts and basal of the tristichopterids (such as Eusthenopteron) and the elpistostegalid fishes.

It was Smith-Woodward (1891) who first grouped Megalichthys, Osteolepis, Thursius, Diplopterus (now Heddleichthys) and Glyptopomus in the family Osteolepidae (correctly the Osteolepididae). Within a paraphyletic "Osteolepididae", Cloutier \& Ahlberg (1996) mentioned that megalichthyids could be recognized as a clade based on several cranial characters referring to Young et al. (1992). Since then, "osteolepiforms" have been unquestionably recognized to be paraphyletic with respect to elpistostegalians and tetrapods (Ahlberg \& Johanson 1998; Cloutier et al. 2020) and the phylogenetic position and status of the Megalichthyidae have continued to be discussed. Fox et al. $(1995$, p. 106) considered the Megalichthyidae to be closer to the "Osteolepididae" than to any other families of "Osteolepiformes". A paraphyletic "Osteolepididae" including a monophyletic group of megalichthyids was also recovered by Ahlberg \& Johanson (1998).

More specifically, Hay (1902) was the first to coin the term "Megalichthyidae", after which Long (1985) suggested synapomorphies to define this particular "osteolepidid" clade, but the first full familial description was not provided until Young et al. (1992). This was later revised by Fox et al. (1995), Borgen and Nakrem (2016), and again most recently by Downs and Daeschler (2020). 
In describing a new species of Megalichthys (M. mullisoni) from the Famennian of USA, Downs and Daeschler (2020) reduced the characters defining the family to three specialised features: (premaxillary tusk that interrupts or lies lingual to the premaxillary marginal tooth row; contact between the subopercular and second [posterior-most] submandibular; and a distinct supratemporal bone), in combination with one plesiomorphic character (cosmine cover on dermal bones).

The family Megalichthyidae includes several taxa from Europe, Russia, Middle East, and North America, but there is only one taxon described from Australia. Cladarosymblema narrienense (Fox et al. 1995) is known from the Lower Carboniferous (Viséan) Raymond Formation in Queensland, Australia, and is the only megalichthyid described from the Southern Hemisphere (Long et al. 2018).

Aside from Cladarosymblema, there are several other genera commonly recognised within the Megalichthyidae: Megalichthys (Agassiz 1835) contains several species found in Devonian-Carboniferous deposits across North America (Cope 1882; Downs \& Daeschler 2020), Morocco (Janvier \& Martin 1979), and the UK (Thomson 1964); Ectosteorhachis nitidus (Cope 1882) is known from the Lower Permian of the USA (Thomson 1964); Sengoerichthys ottoman -considered by some as the earliest megalichthyidfrom the Frasnian of Turkey (Janvier et al. 2007); Palatinichthys laticeps described from the Lower Permian of Germany (Witzmann \& Schoch 2012); and the most recently described megalichthyid genus, Askerichthys heintzi, comes from the Late Carboniferous of Norway (Borgen \& Nakrem 2016). However, Downs and Daeschler (2020) considered that the "unusual combinations of characters" in S. ottoman and $P$. laticeps precluded them from being megalichthyids.

Several other taxa have been considered at times to share affinities with the megalichthyids, but are usually excluded from most analyses due to lacking diagnostic family features or by being too poorly known. Namely, Fox et al. (1995), Janvier et al. (2007) and Witzmann \& Schoch (2012) excluded the lesser-known genera such as the Permo-Pennsylvanian Lohsania from USA (Sumida et al. 2005; Thomson \& Vaughn 1968), Megistolepis and Megapomus from the Devonian of Russia (Vorobyeva 1977), Cryptolepis from the Devonian of Latvia (Lebedev 1995; Vorobyeva 1975), and Mahalalepis (Young et al. 1992) from their studies. The Middle-Late Devonian Mahalalepis resima, from Mount Crean in Antarctica, was named from a single fronto-ethmoidal shield and considered by Young et al. (1992) to be a megalichthyid. If accepted as a megalichthyid, it would represent the oldest member of the clade. Additional material is currently under description and will likely soon more conclusively clarify its taxonomic affinities (Jing Lu, pers. comm.)

In contrast to some of the taxa named above, $C$. narrienense is well known, described on the basis of several 3D-preserved specimens exposed by acid-etching and mechanical preparation. Fox et al. (1995) described in detail many aspects of its anatomy - including the dermal skull bones, braincase, mandible, pectoral girdle and fin, limited elements of the axial skeleton and hyoid arch, as well as the teeth and scales. However, the accessibility of modern scanning techniques today now permits a detailed reexamination of $C$. narrienense to illuminate features of its morphology that remained elusive. Herein we use high-resolution micro-CT $(\mu \mathrm{CT})$ and synchrotron tomography to reveal unseen features not previously described, including elements of the hyoid arch, palatal bones, axial skeleton and a cranial endocast. In doing so several aspects of its morphology are uncovered that prove useful for supporting a more robust clade of the Megalichthyidae, and provide broader resolution in phylogenetic analyses of 
112 this problematic "osteolepidid-grade" of Palaeozoic tetrapodomorph fishes.

113

114

115

116

117

118

119

120

121

122

123

124

125

126

127

128

129

130

131

132

133

134

135

136

137

138

139

140

141

142

143

144

145

146

147

148

\section{MATERIAL \& METHODS}

\section{Material}

Two exceptionally preserved specimens of the megalichthyid, Cladarosymblema narrienense, from the Lower Carboniferous Raymond Formation of the Officer Basin, Queensland, Australia, were scanned using a cabinet micro-CT system or synchrotron tomography to reveal new internal anatomical detail (Supp. Info Fig. 1).

The holotype, housed in the Queensland Museum (QMF 21082), is preserved in a single block of silty limestone and contains the skull, anterior trunk region and both pectoral fins, and was described in detail by Fox et al. (1995). Several bones from the left side of the specimen were removed during preparation at that time so not all paired elements are present on both sides of the specimen, and consequently the right side is the more complete. There are reinforcing metal wires surrounding the perimeter of both pectoral fins.

The second specimen ( $~ 50 \mathrm{~mm}$ in length, $\sim 40 \mathrm{~mm}$ in width) is an isolated ethmosphenoid from the Queensland Museum collection (QMF 21083). This specimen has been acid-prepared, and retains small sections of in-filled limestone within the cranial cavity. There is some slight compression of delicate elements internally but the nasal capsules and hypophyseal region of the endocranium are well preserved.

\section{Scanning \& Segmentation}

The holotype (QMF 21082), although relatively large (dimensions approximately $230 \mathrm{~mm}$ in length, 200 $\mathrm{mm}$ in width, $35 \mathrm{~mm}$ in height), was able to be scanned in 2020 at the Flinders University micro-CT Laboratory using a large-volume micro-CT system (Nikon XTH225 ST, Nikon Metrology Tring, Hertfordshire, UK). The specimen was placed in a polystyrene-foam box (transparent to X-rays), with the long specimen axis vertically aligned with the rotation axis of the micro-CT rotation stage. The specimen was scanned using the following parameters: $160 \mathrm{kV} ; 282 \mu \mathrm{A}(45 \mathrm{~W}), 0.25 \mathrm{~mm}$ tin filter, 2.83 s exposure, rotation step $0.1^{\circ}$ over $360^{\circ}$; with a resulting voxel size of $58 \mu \mathrm{m}$ ( $4056 \times 4056$ pixel detector), containing the entire specimen in the field of view (SI-Figure 1e). The tomographic cross-sections were reconstructed using a filtered back-projection algorithm (Nikon CT Pro 3D software) and saved as 8-bit bitmap format images. A stack of up to 4000 consecutive cross sections was reconstructed, resulting in a height of up to $232 \mathrm{~mm}$. Each cross-section was $3000 \times 1100$ pixels (corresponding to $174 \times 63.8 \mathrm{~mm}$ ) in size. Images were later subsampled by a factor two to a voxel size of $116 \mu \mathrm{m}$ (Perilli et al. 2012).

An isolated ethmosphenoid (QMF 21083) was scanned in 2016 at the Australian Nuclear Science and Technology Organisation (ANSTO) Australian Synchrotron in Melbourne (experiment number AM10403) using the following parameters: $50 \mathrm{kV}, 181^{\circ}$ deg., 1810 projections; angle step $0.1^{\circ}$; exposure time 0.22 
149

150

151

152

153

154

155

156

157

158

159

160

161

162

163

164

165

166

167

168

169

170

171

172

173

174

175

176

177

178

179

180

181

182

183

$\mathrm{sec}$; object to detector $35 \mathrm{~mm}$; with a resultant voxel size of $12.2 \mu \mathrm{m}$.

Reconstructed scan data and associated derived files are deposited on MorphoSource at:

https://www.morphosource.org/dashboard/collections/000383372/edit?locale=en, (or see

Supplementary Information Figure 1 for example reconstructed tomographic slice data). Data were segmented manually using thresholding and rendered in MIMICS V. 18 \& v.19 (Materialise, Leuven, Belgium; http://biomedical.materialise.com/mimics), with Stereolithographs (STL 3D models) of each element exported and available on MorphoSource (https://www.morphosource.org/dashboard/collections/000383372/edit?locale=en\&). Animations were compiled in Adobe Premier Pro.

\section{Phylogenetic Analysis}

The phylogenetic position of the megalichthyids among tetrapodomorphs, as well as the interrelationships among megalichthyids are investigated using the tetrapodomorph character matrix of Cloutier et al. (2020). Cloutier et al.'s (2020) phylogenetic data matrix (comprising 202 characters coded for 43 taxa) was based on 169 characters from Zhu et al. (2017), 13 characters from Daeschler et al. (2006), 11 characters from Swartz (2012) and 5 characters from Cloutier et al. (2020). The new matrix includes 48 taxa.

To the original matrix we included five megalichthyids or taxa assigned to be likely megalichthyids: Sengoerichthys ottoman (Janvier et al. 2007), Palatinichthys laticeps (Witzmann \& Schoch 2012), Askerichthys heintzi (Borgen \& Nakrem 2016), Mahalalepis resima (Young et al. 1992), and Megalichthys mullisoni (Downs \& Daeschler 2020). In addition, we recoded Cladarosymblema based on our new morphological description presented herein, with additional codings for Mahalalepis based on work currently in preparation (Jing Lu, IVPP, pers. comm.) Rather than entering Megalichthys as a composite taxon, we coded M. hibberti and M. laticeps in addition to M. mullisoni all as separate species.

Four new characters are added to Cloutier et al.'s (2020) matrix: characters 203 [Long medioventral process of premaxilla: (0) absent; (1) present]; 204 [Relative size of anterior tectal and lateral rostral: (0) lateral rostral much larger than anterior tectal, (1) lateral rostral and anterior tectal equidimensional, (2) lateral rostral smaller than anterior tectal]; 205 [Size of bones forming the external nares: (0) anterior tectal and lateral rostral similar in size to the posterior tectal, (1) anterior tectal and lateral rostral much smaller than the posterior tectal]; and lastly $\underline{206}$ [Anterolateral process of supratemporal: (0) absent, (1) present].

Simões and Pierce (2021) changed two codings from Cloutier et al.'s (2020) matrix: character $\underline{62}$ (anteromedial process of vomer) for Acanthostega and character 106 (opercular process of hyomandibula) for Panderichthys. We agree solely with the modification suggested for the coding of Acanthostega for character $\underline{62}$. 
184

185

186

187

188

189

190

191

192

193

194

195

196

197

198

199

200

201

202

203

204

205

206

207

208

209

210

211

212

213

214

215

216

217

218

219

220

Thus, we performed parsimony analyses on our matrix (http://morphobank.org/permalink/?P3818), which was coded for 49 taxa (including 5 outgroups) and 206 characters using a heuristic search. Additional comments on codings are contained within the matrix on Morphobank. The tree was rooted on a constrained monophyletic outgroup composed of Youngolepis, Diabolepis, Powichthys, Porolepis, and Glyptolepis. A total of 18 multi-state characters were run ordered; in addition to the morphocline defined in Cloutier et al. (2020, supplementary information) character $\underline{204}$ was considered as a morphocline. Strict, Adams and $50 \%$ majority consensus trees were computed. All analyses were performed in PAUP*v4.0a.

\section{DESCRIPTION}

\section{The Dermal Skull}

On the skull roof, the course of the lateral line canal can be confirmed as lyre-shaped (Fig. 1a,c). It lies close to associated pore group clusters, which are considered likely electroreceptors following the work by King et al. (2018). A network of tubuli in the snout region provides further evidence that Cladarosymblema narrienense likely had some electroreceptive ability. A single bone posterior and disarticulated from the skull roof is confirmed as the median extrascapular (Fig. 1a) due to the presence of the mesial otic sensory-line canal running through it, with no junction for the main otic sensory canal as would be expected in the lateral bones. The cheek bones were described by Fox et al. (1995) and follow a standard basal tetrapodomorph arrangement (Fig. 1a,e,f). Those on the holotype are imperfectly preserved so will not be considered further.

\section{Palate}

Fox et al. (1995) admitted that the palatal bones of Cladarosymblema narrienense were not well known. Those authors pieced together a composite reconstruction of the parasphenoid from several specimens, but failed to recover complete pterygoid bones. The palatoquadrate complex is preserved within the holotype and revealed in the scan data (Fig. 1c,d). It is thin and forms a shallow concavity dorsally. Its margins flex upwards where it abuts the lateral sphenoid portion of the braincase (basipterygoid), the anterolateral face of the oticoccipital and the quadrate articulation posteriorly. In contrast, the posterolateral corner bears a more downturned, smoother edge. Anteriorly the pterygoids are generally flat in the dorsoventral plane, but their posterior half is flexed more into the sagittal plane. In ventral view the right pterygoid bears a longitudinal ridge separating its medial and lateral portions (Fig. 1d).

\section{Submandibular bones}

Concerning the gulars and submandibular bones (Fig. 2a,e,f), Fox et al. (1995) described the lateral (principal) gular of the holotype to have a width of $40 \%$ of its total length, but its width is closer to $35 \%$. There was little to no overlap area in its posteromedial corner for the other gular bone. The median gular is about $30 \%$ of the length of the lateral gulars, thus slightly smaller than the condition in Askerichthys heintzi (c.40\%). It is worthy to note that both Borgen and Nakrem (2016) and Witzmann 
221

222

223

224

225

226

227

228

229

230

231

232

233

234

235

236

237

238

239

240

241

242

243

244

245

246

247

248

249

250

251

252

253

254

255

256

257

258

259

260

and Schoch (2012) numbered the submandibular bones posterior to anterior, whereas Fox et al. (1995) numbered them anterior to posterior. Consequently, this impacts identification of "last" (or second last) submandibular bones that may or may not be overlapped by the subopercular. We choose to follow the convention in numbering these bones from anterior to posterior, whereby the "last" submandibular is the most posterior one. There are in fact seven submandibulars in the holotype (Fig. 2a,e,f), as in Megalichthys sp. and Ectosteorhachis nitidus, although the first one is broken in half. This contrasts with Palatinichthys laticeps which has three submandibulars (Witzmann \& Schoch 2012), and A. heintzi which has six (Borgen \& Nakrem 2016). There is an area for overlap with the subopercular on the last (posterior-most) submandibular only, in contrast to $M$. mullisoni which is said to have contact between the subopercular and the second [last] submandibular (Downs \& Daeschler 2020). There is no evidence of a groove on the underside of the operculum as seen on QMF21105 (Fox et al. 1995).

\section{Mandible}

Fox et al. (1995) were unable to confidently recognise sutures between dermal bones on the mandible on Cladarosymblema narrienense, despite attempting this by using radiographic imaging. The holotype fails to illuminate this further as much of the dermal bone has eroded and the mandible bears a thick cosmine cover (Fig. 2 b-d). These boundaries were also noted to be difficult to ascertain in Askerichthys heintzi (Borgen \& Nakrem 2016) so this may be a feature common among megalichthyids. As discussed in the original description by Fox et al. (1995), it can be confirmed that there is no oral branch of the mandibular canal in the surangular and that the anterior mandibular fossa received the vomerine tusk. The anterior coronoid is longer than the following two, and there are three tusks present (Fig. 2b-d). A. heintzi (and also probably Ectosteorhachis nitiuds) are known to possess just two (Borgen \& Nakrem 2016; Thomson 1964). The parasymphysial tooth plate is known to vary in shape between specimens, that in the holotype forms an elongate triangle covered in small denticles (Fig. 2b,c).

\section{Endocranium and Endocast}

The new data generated permit the reconstruction of the virtual cranial endocast for this taxon. Comparisons are made principally with other tetrapodomorphs for which a full endocast is known, namely Gogonasus andrewsae (Holland 2014), Ectosteorhachis and Megalichthys (Romer 1937), and Eusthenopteron foordi Jarvik 1955 (Stensiö 1963). Other Palaeozoic sarcopterygians with complete endocasts depicted in the literature include the dipnomorph Youngolepis praecursor (Chang 1982), the onychodont Qingmenodus jandemarrai (Lu et al. 2016), the coelacanth Diplocercides kayseri (Stensiö 1963), several lungfish taxa (Challands 2015; Clement \& Ahlberg 2014; Clement et al. 2016; Henderson \& Challands 2018; Miles 1977; Säve-Söderbergh 1952) and the aïstopod Lethiscus stocki (Pardo et al. 2017). Furthermore, partial yet still informative endocasts are known from the stem-tetrapod Tungsenia paradoxa (Lu et al. 2012), porolepiforms Powichthys thorsteinssoni (Clément \& Ahlberg 2010) and Glyptolepis groenlandica (Stensiö 1963), the tetrapodomorph Spodichthys buetleri (Snitting 2008) and early tetrapod genus, Ichthyostega (Clack et al. 2003).

The endocast of the holotype (QMF 21082) measures just over $50 \mathrm{~mm}$ long from the base of the olfactory tracts to the vagus nerve (n.X), and $30 \mathrm{~mm}$ at its widest point across the labyrinths (Fig. 3a,b). As the holotype has suffered some dorsoventral compression during preservation, fine details such as the morphology of the semicircular canals have been lost. Despite this, the gross morphology of the 
261

262

263

264

265

266

267

268

269

270

271

272

273

274

275

276

277

278

279

280

281

282

283

284

285

286

287

288

289

290

291

292

293

294

295

296

297

298

299

endocast can for the first time be revealed in Cladarosymblema narrienense. The isolated ethmosphenoid (QMF 21083) is well-preserved and has only a little localised crushing internally, and so revealed the olfactory and hypophyseal regions particularly well (Fig. $4 \mathrm{~d}-\mathrm{h}$ ).

The overall proportions of the endocast in C. narrienense are similar to those in Y. praecursor, $G$. andrewsae, Megalichthys spp., and Eusthenopteron foordi in having widely separated nasal capsules on long olfactory tracts, a narrow forebrain, but broad mid- and hindbrain regions. This contrasts starkly with the presumed plesiomorphic condition in T. paradoxa - which bears short olfactory tracts and a bulbous telencephalic region.

The nasal capsules are large and rounded with a diameter close to $10 \mathrm{~mm}$, and open ventrally (Fig. $3 \mathrm{~d}-\mathrm{g}$ ). Their posteromesial corners open into wide olfactory tracts that are $15 \mathrm{~mm}$ long and diverge from each other at $50^{\circ}$. The canals for the orbitonasal vein are large and exit the nasal capsules posterolaterally. Several bony tubules project into the medial rostral space from the olfactory tracts which may have housed the anterior cerebral vein, palatine artery or a ramus of maxillaris $\mathrm{nV}_{2}$.

The telencephalic region is short and low, without any obvious ventral expansion as is common in lungfish (Clement \& Ahlberg 2014). Two large canals for the optic nerves exit the cranial cavity laterally marking the anterior extent of the telencephalic region. In contrast, the diencephalic region is both longer and taller, although of comparable width to the telencephalon. A small dorsal protrusion represents a small pineal eminence, seemingly smaller than those in E. foordi and G. andrewsae. In contrast, the hypophyseal fossa is large. The buccohypophyseal duct opens through a large circular aperture ventrally. Two dorsal-most small canals projecting anteriorly from the hypophyseal region likely housed the ophthalmic arteries, in line with but medial to those is a single small canal that might have housed the internal carotid artery. Below this, two slightly larger canals would have carried the palatine arteries. On the left side of the QMF 21083 on the posterior half of the hypophyseal region is a single small canal that could have carried the pituitary vein.

The mesencephalic region of the endocast is considerably broader than the preceding forebrain (Fig. $3 a, b)$. Midway up on the midbrain wall is a canal for the trigeminal nerve (n.V), likely housing both the maxillary and mandibular branches. The rhombencephalic region is very slightly wider than the midbrain, broadening gently towards the labyrinths as in Megalichthys, and in contrast to G. andrewsae which is reconstructed as being narrower in this area. Canals for the vagus nerve (n.X) are visible exiting the cranial cavity posteriorly. Two oval-shaped eminences on the dorsal part of the myelencephalon represent the supraoptic cavities, and the cranial cavity extends a further $14 \mathrm{~mm}$ towards and into the intracranial joint.

Although the specimen has been flattened and undergone some crushing, the origin point of the posterior semicircular canals can be identified (Fig. 3a), so together with the lateral extent of the labyrinth, a rough outline of the vestibular system can be inferred. It is not known how large any utricular recess might have been, but the saccular pouches form tear-drop-shaped outlines in ventral view, with rounded anterior margins tapering posteriorly.

The notochordal canal is broad and probably extended as far forward as to be level with the midbrain, although the bounding bone is not preserved well anteriorly (Fig. 3b,c). 
300

301

302

303

304

305

306

307

308

309

310

311

312

313

314

315

316

317

318

319

320

321

322

323

324

325

326

327

328

329

330

331

332

333

334

335

336

337

\section{Hyoid and Branchial Skeleton}

Most of the elements of the hyoid arch and branchial skeleton are preserved in situ within the holotype and can now be described. The hyomandibular and supposed "urohyals" were described by Fox et al. (1995, fig. 43a-d) but their identification of their "urohyal" is more likely median fin basal elements based on comparison with the new scan data. The urohyal revealed in our articulated specimen is a much-elongated bone with a very wide anterior articulation surface for meeting the basibranchial (more detail on this below).

One complete right hypohyal (and a partial left hypophyal, not figured) sit anterolateral to the basibranchial (Fig. 4a,c,d,f,g). The hypohyal bears a ball-shaped protuberance proximally for articulation with the anterolateral articular facet of the basibranchial (Fig. 4c,d). The distal portion is broadly flared and its shape is similar to those in other tetrapodomorphs, such as Tiktaalik roseae (Downs et al. 2008) and Eusthenopteron foordi (Jarvik 1954; Jarvik 1980). It bears a strong ridge running proximodistally along its dorsal surface, as also seen in Holoptychius bergmanni (Cloutier \& Schultze 1996).

The right ceratohyal (Fig. 4d) is a large, mostly flat tear-drop shaped bone, with a smoothed curved anterior margin. It is marked by a large notch in its posterolateral corner for ligamentous attachment. Its shape differs somewhat from those in G. andrewsae (Long et al. 1997), T. roseae (Downs et al. 2008), and Medoevia lata (Lebedev 1995), which have more elongate and narrower ceratohyals, instead it is more reminiscent of the broader bones found in Glyptolepis groenlandica (Jarvik 1972).

The basibranchial (Fig. 4c) is similar to those in T. roseae (Downs et al. 2008), G. andrewsae (Long et al. 1997), M. lata (Lebedev 1995), and Mandageria fairfaxi (Johanson \& Ahlberg 1997). It forms a slightly elongated heptagonal shape in dorsal view (Fig. 4a-d). The basibranchial is clearly split (in what appears to be a natural margin) into two transverse halves demarcated by mesiolateral angles that separate it into anterior and posterior portions of similar size. The three lateral and posterior margins are scalloped for articulation with the hypobranchials on each side and the hypohyals anterolaterally.

There are four hypobranchials preserved on the right-hand side (Fig. 4c,f,g). The first articulates with the anterior portion of the basibranchial, while the second and third articulate with the posterior half of the basibranchial. The fourth hypobranchial, considerably smaller than the other three, is preserved in loose articulation with the posterior section of the third hypobranchial, as in common among sarcopterygians. There are small gaps between the bones which might have been cartilage-filled in life, but this is not visible in the scan data. The hypobranchials are more elongate than the stouter bones in $T$. roseae (Downs et al. 2008) being more similar to those in M. lata (Lebedev 1995). The first hypobranchial has a broader anterior margin, and its medial margin is curved more strongly, while the second and third have more or less parallel edges and narrower anterior edges. The fourth hypobranchial is about half the size of the preceding three hypobranchials, but with a similar shape to the third hypobranchial with which it articulates.

In ventral view, a sublingual rod and urohyal are preserved underneath the basibranchial in natural articulation (Fig. 4b,d). The sublingual rod is an elongate and narrow bone that tapers slightly anteriorly. It is considerably shorter than that in E. foordi (Jarvik 1980) but of similar length to that in M. lata 
338 (Lebedev 1995). The urohyal is long and rod-like but does not appear to bifurcate posteriorly nor bear a 339 large posterior flange. In this way the urohyal is similar to that in G. andrewsae (Long et al. 1997).

340 Four ceratobranchials are preserved on both left and right sides of the specimen. Three are long and curved measuring about $45 \mathrm{~mm}$ in length, but the fourth is highly reduced and lacks a grooved portion.

342 These are currently under more detailed study in another work currently in preparation by the authors.

343 The general shape of the hyomandibular (Fig. 4c,e) is similar to E. foordi (Jarvik 1980), although it is not 344 so strongly curved in $C$. narrienense. It appears to have been a completely ossified bone, more similar to that in G. andrewsae (Long et al. 1997) and unlike the unfinished one in T. roseae (Downs et al. 2008). Its proximal extremity is double-headed and its distal end contacts the mesial face of a submandibular bone via its opercular process. There is a large opening between the lateral and medial margins of the proximal portion that would have allowed passage of the hyomandibular canal.

\section{Pectoral girdle and fin}

350

351

352

353

354

355

356

357

358

359

360

361

362

363

364

365

366

367

368

369

370

371

372

373

374

375

The pectoral girdle of Cladarosymblema narrienense was described by Fox et al. (1995) from several partial or broken bones. There was no supracleithrum visible in the scan of the holotype, however both clavicles, cleithra and anocleithra well-preserved (Fig. 5a-f). Previously, the anocleithra were represented by just two fragments but both complete bones are observable from the scan data (Fig. $5 e, f)$. The anterior process is about $12 \mathrm{~mm}$ in length and sharply pointed on the left bone, but more rounded on the right-hand side. The posterior flange of the anocleithra is smooth and flat, and measures over $30 \mathrm{~mm}$ in length.

Similarly, Fox et al. (1995) did not have complete cleithra, but these bones can now be described and illustrated (Fig. 5b,d). The cleithra are robust bones with a sizeable branchial lamina. Its external surface is roughened with ornament which consists of irregular tubercles. It has a pointed anterior margin for overlap with the clavicles, but a broad and blunt posterior margin. Although there are some cracks present through this region of the specimen, the cleithrum was a single bone, contra Thomson \& Rackoff (1974).

As described by Fox et al. (1995), the clavicles are indeed about half the size of the cleithra and twisted some $40^{\circ}$ in orientation. Again, the right-hand side bone is better preserved than the left. Its ventral edge is smoothly rounded, while the dorsal surface bears a thickening. The clavicle bears a long ascending process for articulation with the cleithrum. In addition, there is a small, ovoid bone sitting dorsally above the intersection of the clavicles, interpreted as an unornamented interclavicle, the first time this bone has been identified in this taxon (Fig. 5c).

Fox et al. (1995) stated that the scapulocoracoid and its attachment area are larger in C. narrienense than in other osteolepiforms, but in the holotype is not as extensive as the specimen described and illustrated by those authors. Conversely, the scapulocoracoid in fact appears to be smaller and protruding less than those in Eusthenopteron foordi (Jarvik 1980), Megalichthys spp. (Andrews \& Westoll 1970a), and Medoevia lata (Lebedev 1995).

In their original preparation and description of the holotype, Fox et al. (1995) attempted to excavate the appendicular skeleton of the left fin but did not find it, concluding that it must have been poorly 
376

377

378

379

380

381

382

383

384

385

386

387

388

389

390

391

392

393

394

395

396

397

398

399

400

401

402

403

404

405

406

407

408

409

410

411

412

ossified. Their radiographs show an outline of some large metaptyerygial elements of the pectoral fin, but artefacts from the metallic wire supporting the perimeter of the fin limit our potential to find any evidence of any ossified pectoral mesomeres in the remaining pectoral fin area of the holotype. In any case, it can be surmised that these may have even been cartilaginous in $C$. narrienense.

\section{Axial skeleton}

As Fox et al. (1995) described in the original description, vertebral ring centra are preserved that are about 11-12 mm in notochordal diameter, and open dorsally (Fig. $5 \mathrm{~h}, \mathrm{j}, \mathrm{I}$ ). However, those authors fail to figure or describe the neural arches. The neural arches (Fig. $5 \mathrm{~g}, \mathrm{i}, \mathrm{k}$ ) are similar to those figured for Eusthenopteron foordi (Andrews \& Westoll 1970a) and as is common, usually found slightly disarticulated from their associated ring centra (Fig. $5 \mathrm{~h}, \mathrm{j}, \mathrm{I}$ ). The two halves of the neural arch join dorsally to form a neural spine, and these are angled about 35 degrees posteriorly from the vertical plane. The neural arches are flat bones with only a very slight tapering at their dorsal tips.

The elements originally identified by Fox et al. (1995) as two isolated urohyals (QMF 26574 and QMF 26573) are reidentified as a proximal basal plate, perhaps from the second dorsal or anal fin (Fox et al. 1995, fig. 43). The proximal end is narrow, whereas the distal end is approximately three times longer showing three articular facets for the distal radials. The morphology of the proximal basal plate of $C$. narrienense is fairly similar to that observed in E. foordi (Andrews and Westoll 1970, text-fig. 25, 26, 28).

\section{PHYLOGENETIC RESULTS}

Interrelationships among nine species of megalichthyids and the phylogenetic position of megalichthyids among tetrapodomorphs were analysed using a modified version of the tetrapodomorph matrix used by Cloutier et al. (2020). From the original Cladarosymblema narrienense coding in the Cloutier et al. (2020) phylogenetic matrix, an additional ten characters $(72-74,110-112,133,148,190,197)$ were coded based on our new anatomical study. The parsimony analysis (heuristic search) of the complete data matrix (48 taxa, 206 characters) gave 24948 equally parsimonious trees at 494 steps [consistency index $=0.484$, retention index $=0.759$ ], the results from the $50 \%$ majority-rule tree is shown in Figure 6 . The general tetrapodomorph topology is similar to the one obtained by Cloutier et al. (2020). The monophyly of megalichthyids has been recovered in the three consensus trees (strict, Adams, 50\% majority). Megalichthyids are considered the sister-group to canowindrids. "Osteolepidids" (represented by Osteolepis, Gyroptychius, Medoevia, and Gogonasus) form a grade leading to the clade megalichthyids + canowindrids; the inclusion of additional megalichthyids in our analysis regrouped "osteolepidids" at the base of the clade megalichthyids + canowindrids.

Palatinichthys laticeps is the sister-group of the remaining megalichthyids in the three consensus trees, followed by Megalichthys hibberti. In the $50 \%$ majority (Fig. 6a) and strict consensus trees Cladarosymblema forms part of a polytomy including Sengoerichthys, Megalichthyis laticeps and $M$. mullisoni and [Askerichthys + Mahalalepis]. The Adams consensus tree suggests that two of the most 
413

414

415

416

417

418

419

420

421

422

423

424

425

426

427

428

429

430

431

432

433

434

435

436

437

438

439

440

441

442

443

444

445

446

447

448

449

incomplete megalichthyids are responsible for the internal polytomies: Sengoerichthys ottoman (164 unscored and 3 illogical), and Megalichthys laticeps (161 unscored and 6 illogical).

The deletion of the most incomplete megalichthyids [i.e., species with more than $40 \%$ of unscored characters: Mahalalepis resima (173 unscored and 0 illogical), Palatinichthys laticeps (135 unscored and 5 illogical), Askerichthys heintzi (130 unscored and 4 illogical), and Megalichthys mullisoni (92 unscored and 6 illogical)] did not modify the position of the remaining megalichthyids on the tree but reduced considerably both the number of steps (471) and the number of equally parsimonious trees (702). An analysis on 44 taxa including a subset of megalichthyids using the best-known species of Megalichthys (i.e., M. hibberti) and excluding the two most incomplete megalichthyids (i.e., Sengoerichthys ottoman and Mahalalepis resima) provide better resolved megalichthyid interrelationships of 481 steps and 648 equally parsimonious trees (Fig. 6b). The consensus trees recovered the following topology: [Palatinichthys [Megalichthys [Askerichthys, Ectosteorhachis, Cladarosymblema]]].

The monophyly of the megalichthyids is supported by the presence of a long medioventral process of the premaxilla (char. 203), the antero-posterior relationships between the lateral rostral and the anterior tectal relative to the external nostril (character 5; this character could also be phrased as the vertical suture between these two dermal bones at the level of the external nostril). The presence of the anterolateral process of the supratemporal (char. 206) is also shared by most megalichthyids with the exception of Palatinichthys. However, this process is also known in Eusthenopteron, Gyroptychius and Kenichthys. The absence of a pineal foramen (char. 21) characterizes the megalichthyids but is also absent in most of our outgroups.

\section{DISCUSSION}

\section{Systematic Implications}

Cladarosymblema narrienense is significant as the only megalichthyid taxon described from Australia, and along with Mahalalepis resima, one of only two known from Gondwana (Young et al. 1992). Previously unseen morphological details of the cranial endocast, palate, hyoid and branchial skeleton, pectoral girdle and axial skeleton of $C$. narrienense are now elucidated, with additional features confirmed or updated from Fox et al.'s (1995) description. These new data, with additional codings from $M$. resima, and the inclusion of nine megalichthyid species in the parsimony analysis, enabled megalichthyid interrelationships to be reanalysed, with the monophyly of the family confirmed. A full lateral reconstruction of the head of $C$. narrienense is shown in Figure 7, as well as 3D renderings of all segmented bones from the holotype (Fig. 7b-f).

With respect to the phylogenetic status of the Megalichthyidae, Schultze (1974) first identified the specificity of megalichthyids based on the development of the external nares as slit-like openings, partially enclosed by a small posterior tectal bone, and the presence of an intermaxillary process with teeth on the premaxillae. 
450

451

452

453

454

455

456

457

458

459

460

461

462

463

464

465

466

467

468

469

470

471

472

473

474

475

476

477

478

479

480

481

482

483

484

485

486

487

488

Seven characters were originally used by Young et al. (1992) to diagnose the Megalichthyidae: $(Y+1)$ elongate or slit-like external naris; $(Y+2)$ partly enclosed by a posterior tectal bone; $(Y+3)$ presence of an intermaxillary process with teeth on the premaxilla; $(Y+4)$ short and broad vomers with a strong mesial process; $(Y+5)$ closed pineal foramen; $(Y+6)$ parietals ("frontal bones") notched for the posterior nasals; and $(\mathrm{Y}+7)$ well-developed lacrimal notch.

Later using an additional 15 features, Fox et al. (1995) provided a general diagnosis for the Megalichthyidae that was not intended to be a phylogenetic diagnosis, but rather a general differentiation from other "osteolepiforms". Among Fox et al.'s (1995) features that had not been listed by Young et al. (1992), new potential synapomorphies were listed: $(F+1)$ separate bones dorsal and ventral of the narial opening; $(F+2)$ two suboperculars both abutting the posterior-most submandibulars; $(\mathrm{F}+3)$ posterior endocranial wall of trigeminofacialis chamber approximately transverse; and $(\mathrm{F}+4)$ strong symphysial tusk on dentary and teeth reduced or absent in front of it.

Then, while assessing the phylogenetic position of Litoptychius, Coates \& Friedman (2010) mentioned that it shares synapomorphies with megalichthyids including some new neurocranial features: (C\&F1) ethmoid articulation for palatoquadrate extends anterior to postnasal wall; (C\&F2) nerves II and III exit through common foramen; (C\&F3) posteriorly extensive basicranial fenestra; (C\&F4) otico-occipital fissure absent; and (C\&F5) articular surface of quadrate located above ventral margin of the palatoquadrate.

Next, in their exhaustive study on "osteolepiforms", Borgen and Nakrem (2016) reviewed features previously used to diagnose the Megalichthyidae to select 11 of which they identified either as indicative, necessary or sufficient to diagnose the group. Among the unambiguous necessary and sufficient characters, they listed five of their 11 characters (we retain their numbering of characters here): (B\&N1) anterior palatal dental morphology with the presence of anterior premaxillary tusks (in row or posterior to small, same size marginal premaxillary teeth; their "morphotype C and D", respectively) in combination with a cosmine covered surface of the cranium; (B\&N4) the presence of a branch from the supraorbital sensory canal running towards the anterior tectal (their "postnarial"); (B\&N6) a distinct cosmine-less anterior supratemporal (their "intertemporal") process situated mesial to the opening of the sensory canal (i.e., the supraorbital canal); and (B\&N10) a posterior contact between the second submandibular and subopercular and first submandibular.

Most recently, based on the revision provided by Borgen and Nakrem (2016), Downs and Daeschler (2020) reduced the diagnosis to just four synapomorphies: (D\&D1) presence of a cosmine cover on dermal bones; (D\&D2) a premaxillary tusk that interrupts or lies lingual to the premaxillary marginal tooth row (from Young et al. 1992); (D\&D3) contact between the subopercular and the second submandibular bones (from Fox et al. 1995); and (D\&D4) a distinct rostral process of the supratemporal that is without cosmine cover.

Most of these megalichthyid features and synapormophies have already been discussed at length by Fox et al. (1995), Borgen and Nakrem (2016) and Downs and Daeschler (2020). However, additional comments on some of the characters listed above are provided herein. Since Fox et al. (1995), the organization of the bones forming the external naris $(F+1)$ has been recognized as a distinctive feature of 
489

490

491

492

493

494

495

496

497

498

499

500

501

502

503

504

505

506

507

508

509

510

511

512

513

514

515

516

517

518

519

520

521

522

523

524

525

526

megalichthyids. The narial region of megalichthyids in comparison to other "osteolepiforms" necessitates further investigation in order to quantify the size of the naris $(Y+1)$; the relative size of narial surrounding bones $(Y+2$; char. 204, 205); and the precise trajectory of the sensory canals (B\&N4). Although, while megalichthyid external nares seem to be elongated $(Y+1)$, one would have to quantify the shape of the external naris among tetrapodomorphs more broadly to conclusively evaluate this character.

The cheek regions of megalichthyids is poorly known, and although it might reveal some diagnostic features (e.g., shape of the squamosal, shape and height of the dorsal margin of the maxilla, size and orientation of the preopercular) it remains problematic to use these cheek characters diagnostically. The presence of an enlarged anterior tooth on the premaxilla ( $Y+3$ in part, B\&N1 in part, D\&D2; char. 76, 187) and the presence of a long medioventral process of the premaxilla (char. 203) are present in megalichthyids, but the enlarged anterior tooth of the premaxilla is also present in rhizodonts and some "osteolepidids".

The absence of the pineal foramen $(Y+5$; char. 21) was also reported in most of the outgroups used in our analysis; it might well be a plesiomorphic condition or a homoplastic feature among osteichthyans (Janvier et al. 2007). Bjerring (1972) suggested that the anterolateral process of the supratemporal (his "frontodermosphenotic process of the intertemporal" and "area of intertemporal overlapped by dermosphenotic") showing a complex articular structure for the parietal and the intertemporal is characteristic of the Megalichthyidae (Janvier et al. 2007).

The presence of the anterolateral process of the supratemporal (B\&N6 in part, D\&D4; char. 206) is shared by most megalichthyids with the exception of Palatinichthys. However, an anterolateral process on the supratemporal is also present in Eusthenopteron, Eusthenodon, Gyroptychius and Kenichthys. The proportion of the vomer (char. 61), as well as the presence of an anteromedial process of the vomer $(\mathrm{Y}+4$ in part; char. 62), should be quantified properly in order to be compared among tetrapodomorphs. The vomers are much broader than long in megalichthyids and some "osteolepidids" and this is also accurate for the presence of the anteromedial process of the vomer.

Concerning the phylogenetic intrarelationships of the Megalichthyidae, taxa previously considered by some researchers (Downs \& Daeschler 2020; Witzmann \& Schoch 2012) to hold dubious affinities (such as Mahalalepis, Palatinichthys and Sengoerichthys) are confirmed as megalichthyid taxa in our analysis.

Previous phylogenetic analyses included three (Ahlberg \& Johanson 1998; Cloutier et al. 2020; Johanson \& Ahlberg 2001; Simões \& Pierce 2021; Zhu \& Ahlberg 2004; Zhu et al. 2017), four (Young et al. 1992), or five megalichthyids (Witzmann \& Schoch 2012). Thus, our phylogenetic analysis contains the largest megalichthyid diversity included in a phylogenetic analysis with nine species. Megalichthyid intrarelationships recovered from our analysis somewhat resemble that of Witzmann \& Schoch (2012) in nesting Palatinichthys laticeps and Ectosteorhachis nitidus close together, and Cladarosymblema narrienense close to Sengoerichthys ottoman, although the position of Megalichthys differs. We propose that this taxon is unstable, influencing the topology whether considered as one taxon or split into species, and is likely paraphyletic. Future analyses will have to include all anatomical features that have 
527 been previously discussed in the literature with respect to the phylogenetic status of megalichthyid

528 family, genera and species.

529 Revised Diagnosis of the Family Megalichthyidae: Tetrapodomorph fishes at a node higher than

530 Osteolepis and lower than Eusthenopteron which have the following characters: small semi-circular

531 shaped lateral rostral and posterior tectal forming the external nostril dorso-ventrally; premaxilla

532 bearing a well-developed posterior process and tusk that interrupts or lies lingual to the premaxillary

533 marginal tooth row; contact between the subopercular and last (or second last) submandibular; and a

534 distinct supratemporal bone with an anterolateral process lacking cosmine cover.

\section{Palaeoneurology}

537 Increasing access to scanning technologies such as synchrotron, neutron and micro- computed tomography $(\mu \mathrm{CT})$ is advancing palaeontology and in particular the field of "palaeoneurology", yet still very few tetrapodomorph endocasts are known. Consequently, little is understood about changes to brain morphology during this vital period of evolution approaching the fish-tetrapod transition. In particular, the internal space within the braincase, the "endocast" will prove valuable for developing hypotheses about neural evolution within members on the tetrapodomorph stem. In the absence of preserved brains (which are exceedingly rare), evidence from the extant phylogenetic bracket (lobefinned fish and amphibians) suggests that it may be possible to make some inferences about the size of certain brain regions from the shape of the endocast alone (Challands et al. 2020; Clement et al. 2021; Clement et al. 2015).

Megalichthys nitidus (Romer 1937) and Eusthenopteron foordi (Stensiö 1963) had their endocasts manually reconstructed in detail via Sollas' painstaking and destructive grinding method popularized by the Stockholm School (Schultze 2009). Partial virtual endocasts (ethmosphenoids) have been described more recently of the stem-tetrapod, Tungsenia paradoxa (Lu et al. 2012), and the "osteolepiform" Spodichthys buetleri (Snitting 2008) from CT data. To date, Gogonasus andrewsae (Holland 2014) remains the only tetrapodomorph for which its full braincase has been investigated via tomographic data, but while the neurocranium was described in detail, a full endocast was neither figured nor described.

With respect to early tetrapod endocasts, a small section of an eroded Ichthyostega stensioei braincase was figured in Clack et al. (2003) illustrating a portion of the oticoccipital, Pardo et al. (2017) figured an endocast from the Early Carboniferous aïstopod, Lethiscus stocki, and the endocast was described from the Permian temnospondyl, Eryops megacephalus (Dempster 1935).

Thus, the description of the endocast of Cladarosymblema narrienense provides a valuable addition enabling new insight into the neurobiology of the tetrapod stem group. C. narrienense and $E$. foordi have olfactory tracts shorter and broader than those in M. nitidus and G. andrewsae. The nasal capsules are widely separated from each other and positioned on long olfactory canals, and the forebrain is narrow in all known tetrapodomorphs (except for T. paradoxa), with the mid and hindbrain regions 
566

567

568

569

570

571

572

573

574

575

576

577

578

579

580

581

582

583

584

585

586

587

588

589

590

591

592

593

594

595

596

597

598

599

600

601

602

603

604

diversity appears to exist in the endocasts of a comparable group, Palaeozoic lungfish, compared to all known stem tetrapods (Clement et al. Preprint).

The hypophyseal fossa is another region of the braincase that bears further consideration here. The orientation of the hypophyseal region varies among taxa with T. paradoxa (Lu et al. 2012), Diplocercides kayseri (Stensiö 1963), Youngolepis praecursor (Chang 1982) and most lungfish (Clement et al. 2016) having small, ventrally-directed hypophyseal fossae. In contrast, E. foordi (Stensiö 1963), S. buetleri (Snitting 2008), G. andrewsae (Holland 2014), Qingmenodus jandemarrai (Lu et al. 2016) and several Palaeozoic actinopterygians (Giles \& Friedman 2014) have thinner and narrower ones that extend considerably further ventrally. In $C$. narrienense and $M$. nitidus the hypophyseal fossa is a more robust structure, extending ventrally from the cranial cavity but with a sizeable anteriorly-projecting lobe. $D$. kayseri and $Y$. praecursor also have significant lobes on their hypophyseal fossae, but these are oriented posteriorly in those taxa.

The anteriorly-oriented space in the hypophyseal region of megalichthyids may potentially accommodate the pars tuberalis as hypothesised for T. paradoxa and Glyptolepis groenlandica (Lu et al. 2012). The pars tuberalis is part of the pituitary gland and is present in all tetrapods but particularly well developed in mammals (Kardong 2006). It is thought to play a role in sensing photoperiod and was taken as supporting evidence that some brain modifications in stem tetrapods for an increasingly terrestrial lifestyle had appeared as long ago as the Early Devonian (Lu et al. 2012). However, the pars tuberalis, when present, is only a very small upgrowth around the stalk of the infundibulum and may potentially be too small to be reflected in some endocasts. In fact, it is not recognisable in a recent investigation of some extant salamanders (Challands et al. 2020) nor frog and caecilian endocasts (Clement et al. 2021). This is not to say that animals lacking a pars tuberalis were not sensitive to photoperiod, as even extant fishes which lack a pars tuberalis (chondrichthyans and teleosts) can, for example, sense seasonal changes in day length via their saccus vasculosus instead (Nakane et al. 2013). However, we suggest that the enlarged anterior lobe of the hypophyseal region as seen in $C$. narrienense most likely accommodates an expanded pars distalis. The pars distalis consists of secretory cells and comprises the bulk of the adenohypophysis ("anterior lobe" of the pituitary) which plays a large role in the production of numerous hormones (Romer \& Parsons 1985).

\section{CONCLUSIONS}

Synchrotron and $\mu \mathrm{CT}$ of two well-preserved 3D specimens of Cladarosymblema narrienense confirm and update the original description of this taxon, in addition to revealing never-before-seen details of its anatomy, enabling a more comprehensive understanding of the only Australian megalichthyid. This work highlights the value of tomography to supplement traditional preparation and descriptions of key fossil specimens. New details -particularly of the palatoquadrate complex, hyoid and branchial arches, pectoral girdle, and axial skeletons- greatly increase our understanding of this "osteolepidid-grade" tetrapodomorph, boosting our knowledge of the total morphological diversity within this group. In addition, while several cranial endocasts are known from manual reconstructions or isolated 
605

606

607

608

609

610

611

612

613

\section{4}

615

616

617

618

619

620

621

622

623

624

625

626

627

628

629

630

631

632

633

634

635

636

637

638

639

ethmosphenoids, $C$. narrienense enables the reconstruction and visualisation of the first full virtual (from tomographic data) cranial endocast of a tetrapodomorph fish, enabling greater insight into their neurobiological condition, including characteristics of note such as the size and shape of the pituitary gland. A new phylogenetic analysis confirms the monophyly of the Megalichthyidae, which includes seven genera (Askerichthys, Cladarosymblema, Ectosteorhachis, Mahalalepis, Megalichthys, Palatinichthys and Sengoerichthys), and their position within Tetrapodomorpha more broadly. An updated familial diagnosis is provided.

\section{Acknowledgements}

We are grateful to Scott Hocknull and Kristen Spring (Queensland Museum) for specimen loans. We thank Vincent Dupret (Uppsala University) for assistance with synchrotron scanning and access to beamtime, and acknowledge Flinders Microscopy and Micro Analysis (FMMA) for providing access to the large-volume micro-CT system.

\section{Figure Captions}

Figure 1. Micro-CT 3D rendering (58 $\mu \mathrm{m}$ pixel size) of dermal skull and braincase of Cladarosymblema narrienense (QMF 21082). A, skull in dorsal view showing placement of bones on holotype; $B$, braincase in ventral view; dermal skull bones, braincase and palatal bones in $C$, dorsal and $D$, ventral view; $E$, skull and cheek in right lateral view.

Figure 2. Micro-CT 3D rendering (58 $\mu \mathrm{m}$ pixel size) of mandible and submandibular bones of Cladarosymblema narrienense (QMF 21082). A, mandibular bones in ventral view showing placement of bones on holotype; mandible in B, dorsal; C, lingual; and D, labial view. E-F, gulars and submandibular bones shown in isolation, in ventral and dorsal view.

Figure 3. Micro-CT 3D (58 $\mathrm{mm}$ pixel size) and synchrotron rendering (12 $\mu \mathrm{m}$ pixel size) of cranial endocast and sensory lines of Cladarosymblema narrienense (QMF 21082/3). A, dorsal; $b$, ventral; and $C$, left lateral view; QMF 21083 in $D, E$, dorsal view; $F, G$, ventral view; $H$, left lateral view showing zoomed in hypophysial fossa region.

Figure 4. Micro-CT 3D rendering (58 $\mu \mathrm{m}$ pixel size) of hyoid and branchial skeleton of Cladarosymblema narrienense (QMF 21082). A, skull in dorsal view showing placement of bones on holotype; B, in ventral view; C,D, full hyoid and basibranchial skeleton including ceratobranchials as preserved in situ; E, closeup of left hyomandibular; and right hypobranchials 1-4 in F, ventral and G, dorsal view.

Figure 5. Micro-CT 3D rendering (58 $\mu \mathrm{m}$ pixel size) of pectoral and axial elements of Cladarosymblema narrienense (QMF 21082). A, ventral view, and B, in dorsal view, showing placement of bones on 
640

641

642

643

644

645

646

647

648

649

650

651

652

653

654

655

656

657

658

659

660

661

662

663

664

665

666

667

668

669

670

671

672

673

674

675

676

677

678

679 holotype; pectoral girdle in $C$, dorsal view; and D, ventral view; $E, F$, anocleithra in alternate views; and neural arches in $\mathrm{G}$, lateral; I, dorsal; $\mathrm{K}$, ventral view; ring centra in $\mathrm{H}$, lateral; J, dorsal; L, ventral view.

Figure 6. Parsimony analyses. A, 50\% majority-rule consensus tree from parsimony analysis with inclusion of all taxa showing monophyly of the Megalichthyidae; B, Canowindrid + Megalichthyid sub-set with most incomplete taxa excluded (Mahalalepis, M. mullisoni, M. laticeps, Sengoerichthys) provides greater resolution of megalichthyid phylogeny. Image silhouettes are authors own (elpistostegalid, rhizodont, megalichthyid, canowindrid) or from PhyloPic http://phylopic.org/ (Ichthyostega, Scott Hartman; Eusthenopteron \& Gogonasus, Michael Keesey).

Figure 7. Cladarosymblema narrienense. A, Lateral head reconstruction of Cladarosymblema narrienense, compiled from Fox et al. (1995) and new data. Colour-coded as follows: dermal skull roof (dark blue), cheek (light blue), lower jaw (pale green), opercular series (purple), and pectoral (dark green). Bones marked with "?" remain unknown in this taxon. B-E, micro-CT 3D rendering of all segmented bones in the holotype (QMF 21082): B, dorsal view; C, ventral view; D, anterolaterodorsal view; and $\mathrm{E}$, posteroventrolateral view.

SI-Figure 1. Tomographic data example slice of A,B, holotype QMF 20182 (Micro-CT 3D rendering, scan performed at $58 \mu \mathrm{m}$ pixel size), and C,D, QMF 21083 (synchrotron-CT rendering, scan performed at 12 $\mu \mathrm{m}$ pixel size); E, X-ray image of holotype QMF 20182 showing total field of view and X-ray attenuation, F, photograph of holotype QMF 20182 in dorsal showing condition of specimen. 
680

681

682

683

684

685

686

687

688

689

690

691

692

693

694

695

696

697

698

699

700

701

702

703

704

705

706

707

708

709

710

711

712

713

714

715

716

717

718

719

720

721

722

723

724

725

726

Clement AM, and Ahlberg PE. 2014. The first virtual cranial endocast of a lungfish (Sarcopterygii: Dipnoi). PloS One 9:e113898. 10.1371/journal.pone.0113898

Clement AM, Challands TJ, Cloutier R, Houle L, Ahlberg PE, Collin S, and Long JA. Preprint. Morphometric Analysis of Lungfish Endocasts Elucidates Early Dipnoan Palaeoneurological Evolution. eLife.

Clement AM, Challands TJ, Long JA, and Ahlberg PE. 2016. The cranial endocast of Dipnorhynchus sussmilchi (Sarcopterygii: Dipnoi) and the interrelationships of stem-group lungfishes. PeerJ 4:e2539. 10.7717/peerj.2539

Clement AM, Mensforth CL, Challands TJ, Collin SP, and Long JA. 2021. Brain Reconstruction Across the Fish-Tetrapod Transition; Insights from Modern Amphibians. Frontiers in Ecology and Evolution 9:60. doi: 10.3389/fevo.2021.640345

Clement AM, Nysjö J, Strand R, and Ahlberg PE. 2015. Brain - endocast relationship in the Australian lungfish, Neoceratodus forsteri, elucidated from tomographic data (Sarcopterygii: Dipnoi). PloS One 10:e0141277. DOI: 10.1371/journal.pone.0141277

Clément G, and Ahlberg PE. 2010. The endocranial anatomy of the early sarcopterygian Powichthys from Spitsbergen, based on CT scanning. In: Elliott DK, Maisey JG, Yu X, and Miao D, eds. Morphology, Phylogeny and Paleobiogeography of Fossil Fishes: honoring Meemann Chang. Munich: Dr. Friedrich Pfeil, 363-377.

Cloutier R, and Ahlberg PE. 1996. Morphology, characters and interrelationships of basal Sarcopterygians. In: Stiassny ML, Parenti LR, and Johnson GD, eds. Interrelationships of Fishes. San Diego: Academic Press, 445-479.

Cloutier R, Clement AM, Lee MSY, Noël R, Béchard I, Roy V, and Long JA. 2020. Elpistostege and the origin of the vertebrate hand. Nature 579:549-554. https://doi.org/10.1038/s41586-020-2100-8

Cloutier R, and Schultze H-P. 1996. Porolepiform fishes (Sarcopterygii). 248-270.

Coates MI, and Friedman M. 2010. Litoptychus bryanti and characteristics of stem tetrapod neurocrania. In: Elliott DK, Maisey JG, Yu X-B, and Miao D, eds. Morphology, phylogeny and paleobiogeography of fossil fishes. München: Verlag Dr. Friedrich Pfeil, 389-416.

Cope ED. 1882. On some new and little known Paleozoic vertebrates. Proceedings of the American Philosophical Society 30:221-229.

Daeschler EB, Shubin N, and Jenkins FAJ. 2006. A Devonian tetrapod-like fish and the evolution of the tetrapod body plan. Nature 440:757-763.

Dempster WT. 1935. The brain case and endocranial cast of Eryops megacephalus (Cope). Journal of Comparative Neurology 62.

Downs JP, and Daeschler EB. 2020. A New Species of Megalichthys (Sarcopterygii, Megalichthyidae) from the Upper Devonian (Famennian) of Pennsylvania, U.S.A., and a Report on the Cosmine-Covered Osteolepiform Fossils of the Catskill Formation. Journal of Vertebrate Paleontology. DOI: 10.1080/02724634.2020.1774771

Downs JP, Daeschler EB, Jenkins FAJ, and Shubin NH. 2008. The cranial endoskeleton of Tiktaalik roseae. Nature 455:925-929.

Fox RC, Campbell KSW, Barwick RE, and Long JA. 1995. A new osteolepiform fish from the Lower Carboniferous Raymond Formation, Drummond Basin, Queensland. Memoirs of the Queensland Museum 38:97-221.

Giles S, and Friedman M. 2014. Virtual Reconstruction of Endocast Anatomy in Early Ray-Finned Fishes (Osteichthyes, Actinopterygii). Journal of Paleontology 88:636-651.

Hay OP. 1902. Bibliography and catalogue of the fossil Vertebrata of North America (No. 179). US Government Printing Office.

Henderson SAC, and Challands TJ. 2018. The cranial endocast of the Upper Devonian dipnoan 'Chirodipterus' australis. PeerJ 6:e5148. DOI 10.7717/peerj.5148 
727

728

729

730

731

732

733

734

735

736

737

738

739

740

741

742

743

744

745

746

747

748

749

750

751

752

753

754

755

756

757

758

759

760

761

762

763

764

765

766

767

768

769

770

771

772

773

Holland T. 2014. The endocranial anatomy of Gogonasus andrewsae Long, 1985 revealed through micro CT-scanning. Earth and Environmental Science Transactions of the Royal Society of Edinburgh 105:9-34.

Janvier P, Clément G, and Cloutier R. 2007. A primitive megalichthyid fish (Sarcopterygii, Tetrapodomorpha) from the Upper Devonian of Turkey and its biogeographical implications. Geodiversitas 29:249-268.

Janvier P, and Martin M. 1979. Les Vertebres Devoniens De L'iran Central li - Coelacanthiformes, Struniiformes, Osteolepiformes. Geobios 12:497-511.

Jarvik E. 1954. On the visceral skeleton in Eusthenopteron with a discussion of the parasphenoid and palatoquadrate in fishes. Almqvist \& Wiksells 5.

Jarvik E. 1972. Middle and Upper Devonian Porolepiformes from East Greenland with Special Reference to Glyptolepis groenlandica n. sp. and a Discussion on the Structure of the Head in the Porolepiformes. Meddelelser om Gronland 187:1-307.

Jarvik E. 1980. Basic Structure and Evolution of Vertebrates. London: Academic Press.

Johanson Z. 2004. Late Devonian sarcopterygian fishes from eastern Gondwana (Australia and Antarctica) and their importance in phylogeny and biogeography. In: Arratia G, Wilson MVH, and Cloutier R, eds. Recent Advances in the Origin and Early Radiation of Vertebrates. Munich, Germany: Verlag Dr. Friedrich Pfeil, 287-308.

Johanson Z, and Ahlberg PE. 1997. A new tristichopterid (Osteolepiformes: Sarcopterygii) from the Mandagery Sandstone (Late Devonian, Famennian) near Canowindra, NSW, Australia. Transactions of the Royal Society of Edinburgh: Earth Sciences 88:39-68.

Johanson Z, and Ahlberg PE. 2001. Devonian rhizodontids and tristichopterids (Sarcopterygii; Tetrapodomorpha) from East Gondwana. Transactions of the Royal Society of Edinburgh: Earth Sciences 92:43-74.

Kardong KV. 2006. Vertebrates: Comparative Anatomy, Function, Evolution. New York: McGraw Hill. King B, Hu Y, and Long JA. 2018. Electroreception in early vertebrates: survey, evidence and new information. Palaeontology:1-34. doi: 10.1111/pala.12346

Lebedev OA. 1995. Morphology of a new osteolepidid fish from Russia. Bulletin du Muséum national d'Histoire naturelle, Paris 4e Série Section C Sciences de la Terre Paléontologie, Géologie, Minéralogie 17:287-341.

Long J, Clement AM, and Choo B. 2018. New insights into the origins and radiation of the mid-Palaeozoic Gondwanan stem tetrapods. Earth and Environmental Science Transactions of the Royal Society of Edinburgh:1-17. https://doi.org/10.1017/S1755691018000750

Long JA. 1985. A new osteolepid fish from the Upper Devonian Gogo Formation of Western Australia. Records of the Western Australian Museum 12:361-377.

Long JA, Barwick RE, and Campbell KSW. 1997. Osteology and functional morphology of the osteolepiform fish Gogonasus andrewsae Long, 1985, from the Upper Devonian Gogo Formation, Western Australia. Records of the Western Australian Museum Supplement 53:1-89.

Lu J, Zhu M, Ahlberg PE, Qiao T, Zhu Y, Zhao W, and Jia LT. 2016. A Devonian predatory fish provides insights into the early evolution of modern sarcopterygians. Science Advances 2:1-8.

Lu J, Zhu M, Long JA, Zhao W, Senden TJ, Jia LT, and Qiao T. 2012. The earliest known stem-tetrapod from the Lower Devonian of China. Nature Communications 3:1160. DOI: 10.1038/ncomms2170

Miles RS. 1977. Dipnoan (lungfish) skulls and the relationships of the group: a study based on new species from the Devonian of Australia. Zoological Journal of the Linnean Society 61:1-328.

Nakane Y, Ikegami K, ligo M, Ono H, Takeda K, Takahashi D, Uesaka M, Kimijima M, Hashimoto R, Arai N, and Suga T. 2013. The saccus vasculosus of fish is a sensor of seasonal changes in day length. Nature Communications 4:p.2108. 
774

775

776

777

778

779

780

781

782

783

784

785

786

787

788

789

790

791

792

793

794

795

796

797

798

799

800

801

802

803

804

805

806

807

808

809

810

811

812

813

814

815

816

817

818

819
Pardo JD, Szostakiwskyj M, Ahlberg PE, and Anderson JS. 2017. Hidden morphological diversity among early tetrapods. Nature 546:642-645. doi:10.1038/nature22966

Perilli E, Parkinson IH, and Reynolds KJ. 2012. Micro-CT examination of human bone: from biopsies towards the entire organ. Annali dell'Istituto superiore di sanita 48:75-82.

Romer AS. 1937. The braincase of the Carboniferous Crossopterygian Megalichthys nitidus. Bulletin of the Museum of Comparative Zoology 132:1-73.

Romer AS, and Parsons TS. 1985. The Vertebrate Body.

Säve-Söderbergh G. 1952. On the skull of Chirodipterus wildungensis Gross, an Upper Devonian dipnoan from Wildungen. Kunglinga Svenska Vetenskapsakademiens Handlingar 4 3:1-29.

Schultze H-P. 1974. Osteolepidide Rhipidistia (Pisces) aus dem Pennsylvanian von Illinois/USA. Neues Jahrbuch für Geologie und Paläontologie, Abhandlungen 146:29-50.

Schultze H-P. 2009. The international influence of the Stockholm School. Acta Zoologica 90:22-37.

Simões TR, and Pierce SE. 2021. Sustained high rates of morphological evolution during the rise of tetrapods. Nature Ecology and Evolution:1-12. https://doi.org/10.1038/s41559-021-01532-x

Smith-Woodward AS. 1891. Catalogue of the fossil fishes in the British Museum. Part 2. London. p 567.

Snitting D. 2008. A redescription of the anatomy of the Late Devonian Spodichthys buetleri Jarvik, 1985 (Sarcopterygii, Tetrapodomorpha) from East Greenland. Journal of Vertebrate Paleontology 28:637-655.

Stensiö E. 1963. The Brain and the Cranial Nerves in Fossil, Lower Craniate Vertebrates. Skrifter utgitt av Det Norske Videnskaps-Akademi:1-120.

Sumida SS, Scott KM, and Wideman N. 2005. New Crossopterygian Material from the Late Paleozoic of Southeastern Utah. New Mexico Museum of Natural History and Science Bulletin 30:307-314.

Swartz B. 2012. A marine stem-tetrapod from the Devonian of Western North America. PloS One 7:1-11? doi:10.1371/journal.pone.0033683

Thomson KS. 1964. Revised Generic Diagnoses Of The Fossil Fishes Megalichthys And Ectosteorhachis (Family Osteolepidae). Bulletin of the Museum of Comparative Zoology 131:283-311.

Thomson KS, and Rackoff JS. 1974. The shoulder girdle of the Permian rhipidistian fish Ectosteorhachis nitidus Cope: structure and possible function. Journal of Paleontology 48:170-179.

Thomson KS, and Vaughn PP. 1968. Vertebral structure in Rhipidistia (Osteichthyes, Crossopterygii) with description of a new Permian genus. Peabody Museum of Natural History 127:1-19.

Vorobyeva El. 1975. An osteolepid crossopterygian from the Ketleri Formation of Latvia. In: A. GA, ed. Fauna and Stratigraphy of the Palaeozoic and Mesozoic of Baltics and Byelorussia. Mintis, Vilnius, 233-237.

Vorobyeva El. 1977. Morphology and evolution of sarcopterygian fishes. Trudy Paleontologischeskogo Instituta Akademia, Nauk SSSR 163:1-239.

Witzmann F, and Schoch RR. 2012. A megalichthyid sarcopterygian fish from the Lower Permian (Autunian) of the Saar-Nahe Basin, Germany. Geobios 45:241-248.

Young GC, Long JA, and Ritchie A. 1992. Crossopterygian fishes from the Devonian of Antarctica: systematics, relationships and biogeographic significance. Records of the Australian Museum Supplement 14:1-77.

Zhu M, and Ahlberg PE. 2004. The origin of the internal nostril of tetrapods. Nature 432:94-97. 10.1038/nature02843

Zhu M, Ahlberg PE, Zhao W-J, and Jia L-T. 2017. A Devonian tetrapod-like fish reveals substantial parallelism in stem tetrapod evolution. Nature Ecology and Evolution. DOI: 10.1038/s41559-0170293-5

Peer] reviewing PDF | (2021:09:66190:1:1:NEW 11 Nov 2021) 
Figure 1

Figure 1. Micro-CT 3D rendering ( $58 \mu \mathrm{m}$ pixel size) of dermal skull and braincase of Cladarosymblema narrienense (QMF 21082).

A, skull in dorsal view showing placement of bones on holotype; $B$, braincase in ventral view; dermal skull bones, braincase and palatal bones in C, dorsal and D, ventral view; E, skull and cheek in right lateral view. 

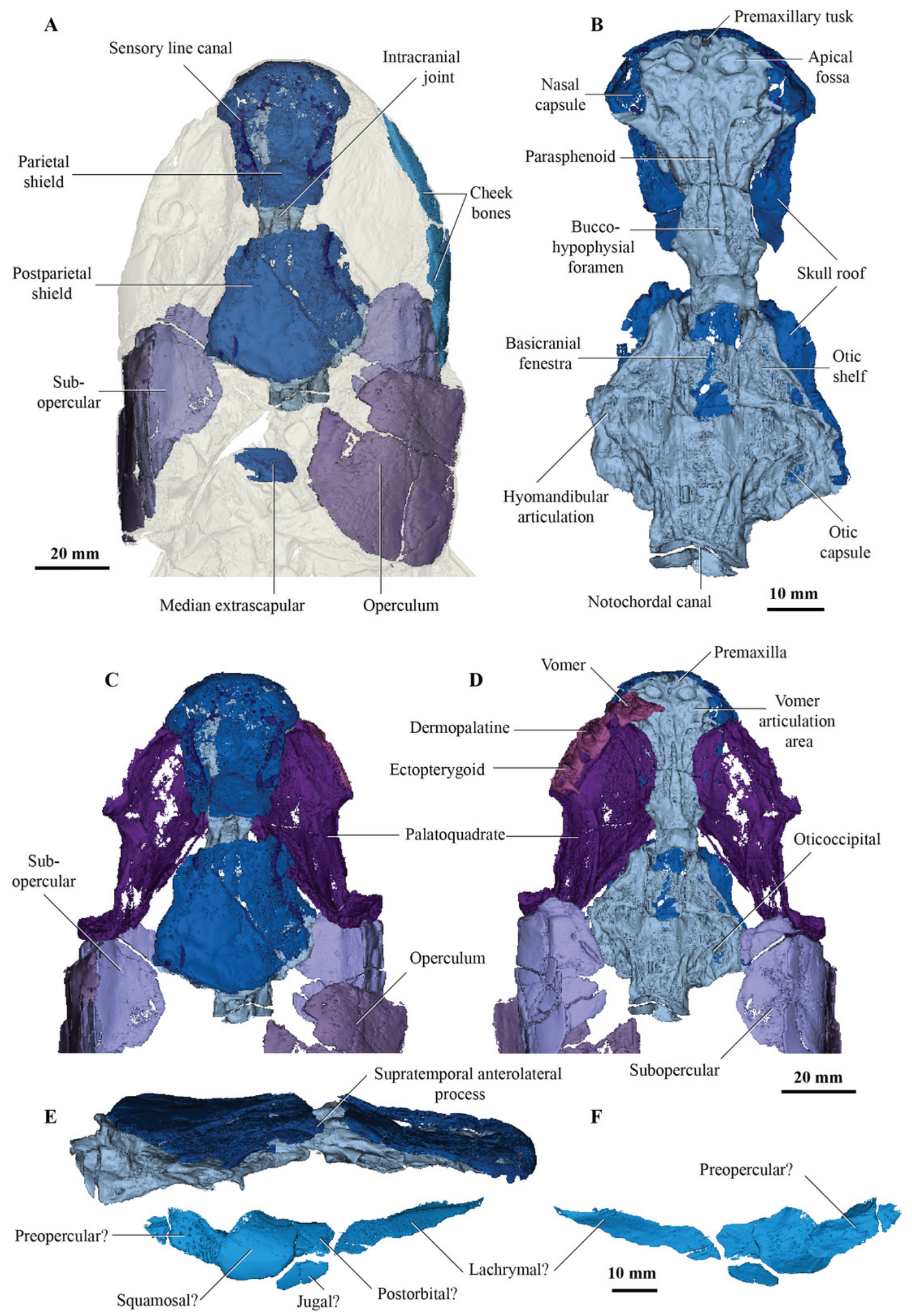


\section{Figure 2}

Figure 2. Micro-CT 3D rendering ( $58 \mu \mathrm{m}$ pixel size) of mandible and submandibular bones of Cladarosymblema narrienense (QMF 21082).

A, mandibular bones in ventral view showing placement of bones on holotype; mandible in $B$, dorsal; C, lingual; and D, labial view. E-F, gulars and submandibular bones shown in isolation, in ventral and dorsal view.

$\mathbf{A}$

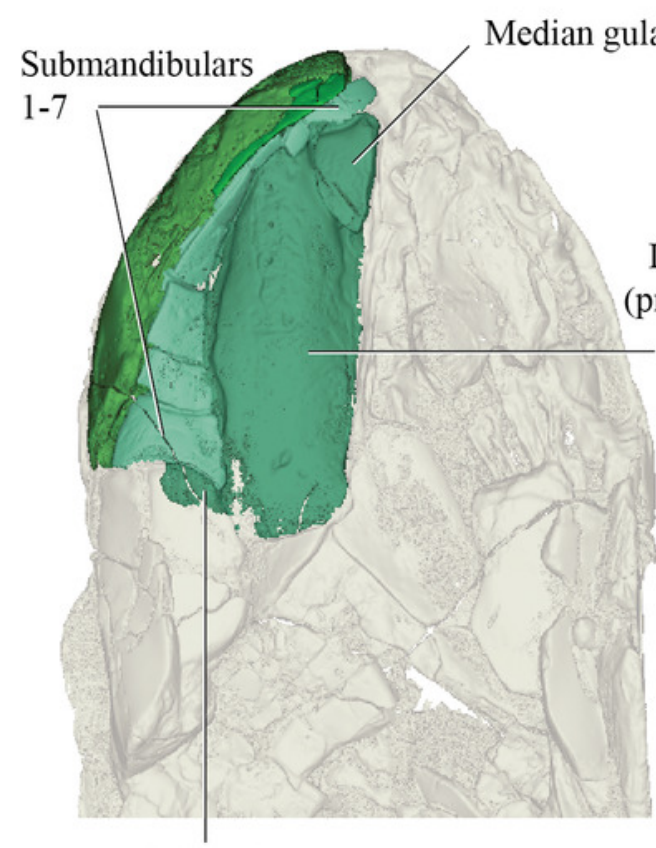

Point of contact

with subopercular

$\mathbf{E}$

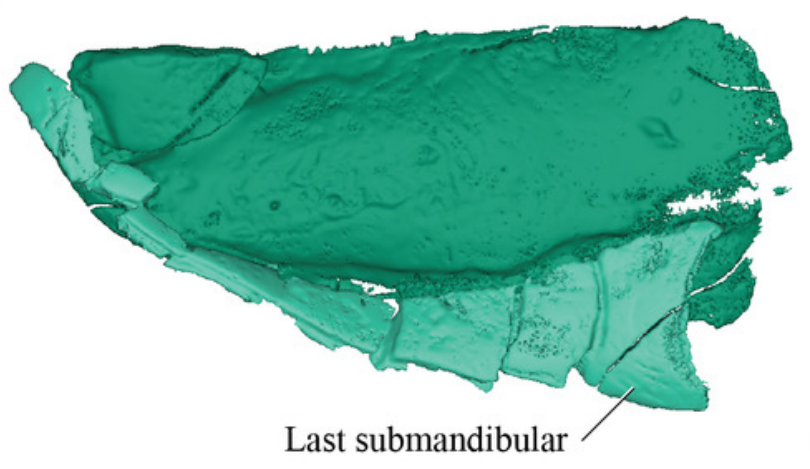

B

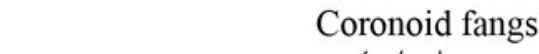

Precoronoid fossa

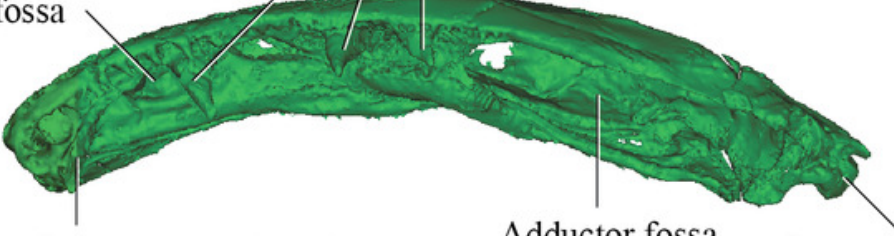

Parasymphysial tooth plate

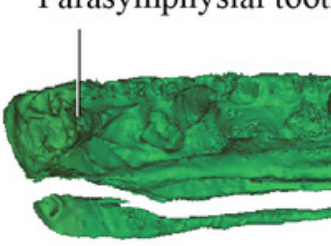

D

Prearticular
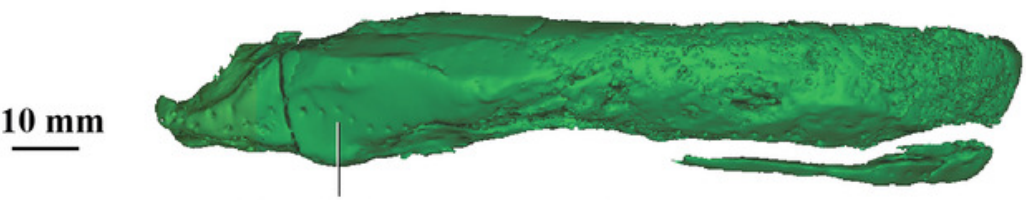

Mandibular sensory canal

$10 \mathrm{~mm}$

Median gular
F

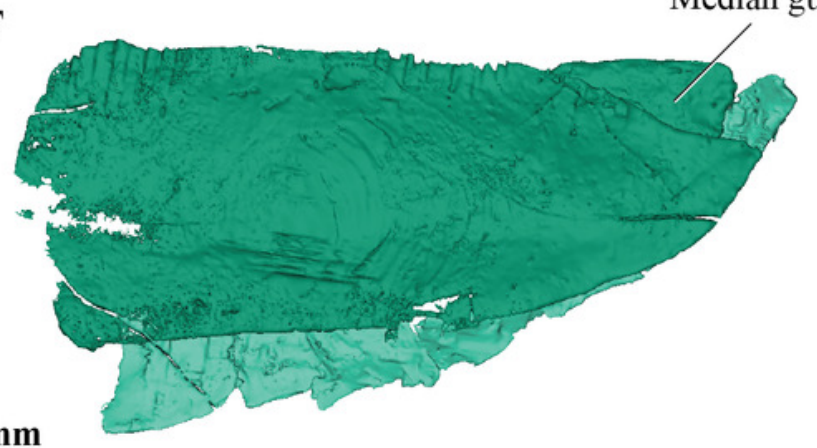


Figure 3

Figure 3. Micro-CT 3D (58 $\mu \mathrm{m}$ pixel size) and synchrotron rendering ( $12 \mu \mathrm{m}$ pixel size) of cranial endocast and sensory lines of Cladarosymblema narrienense (QMF 21082/3).

A, dorsal; b, ventral; and C, left lateral view; QMF 21083 in D,E, dorsal view; F, G, ventral view; $\mathrm{H}$, left lateral view showing zoomed in hypophysial fossa region. 


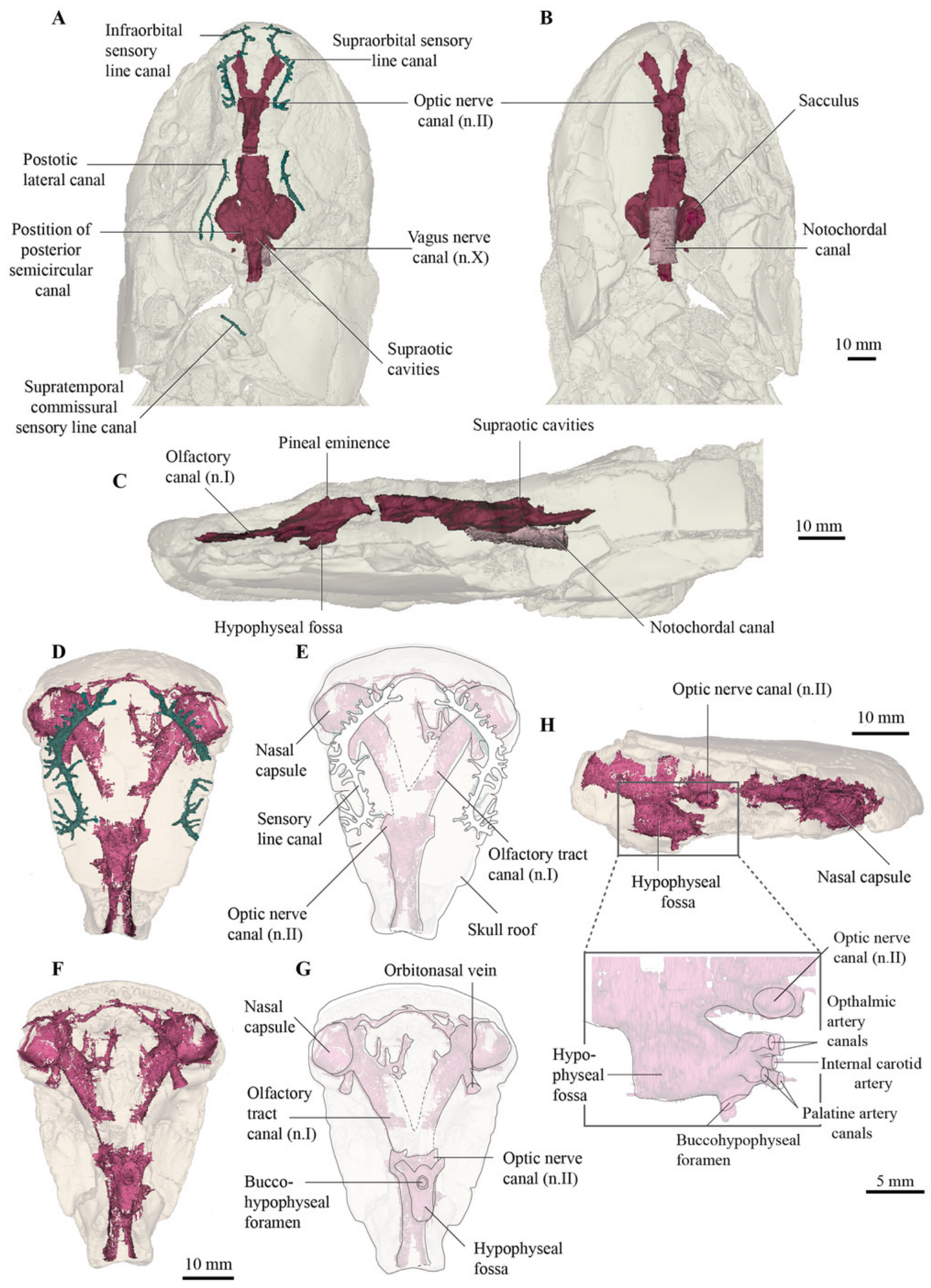


Figure 4

Figure 4. Micro-CT 3D rendering ( $58 \mu \mathrm{m}$ pixel size) of hyoid and branchial skeleton of Cladarosymblema narrienense (QMF 21082).

A, skull in dorsal view showing placement of bones on holotype; B, in ventral view; C,D, full hyoid and basibranchial skeleton including ceratobranchials as preserved in situ; E, closeup of left hyomandibular; and right hypobranchials 1-4 in F, ventral and G, dorsal view. 

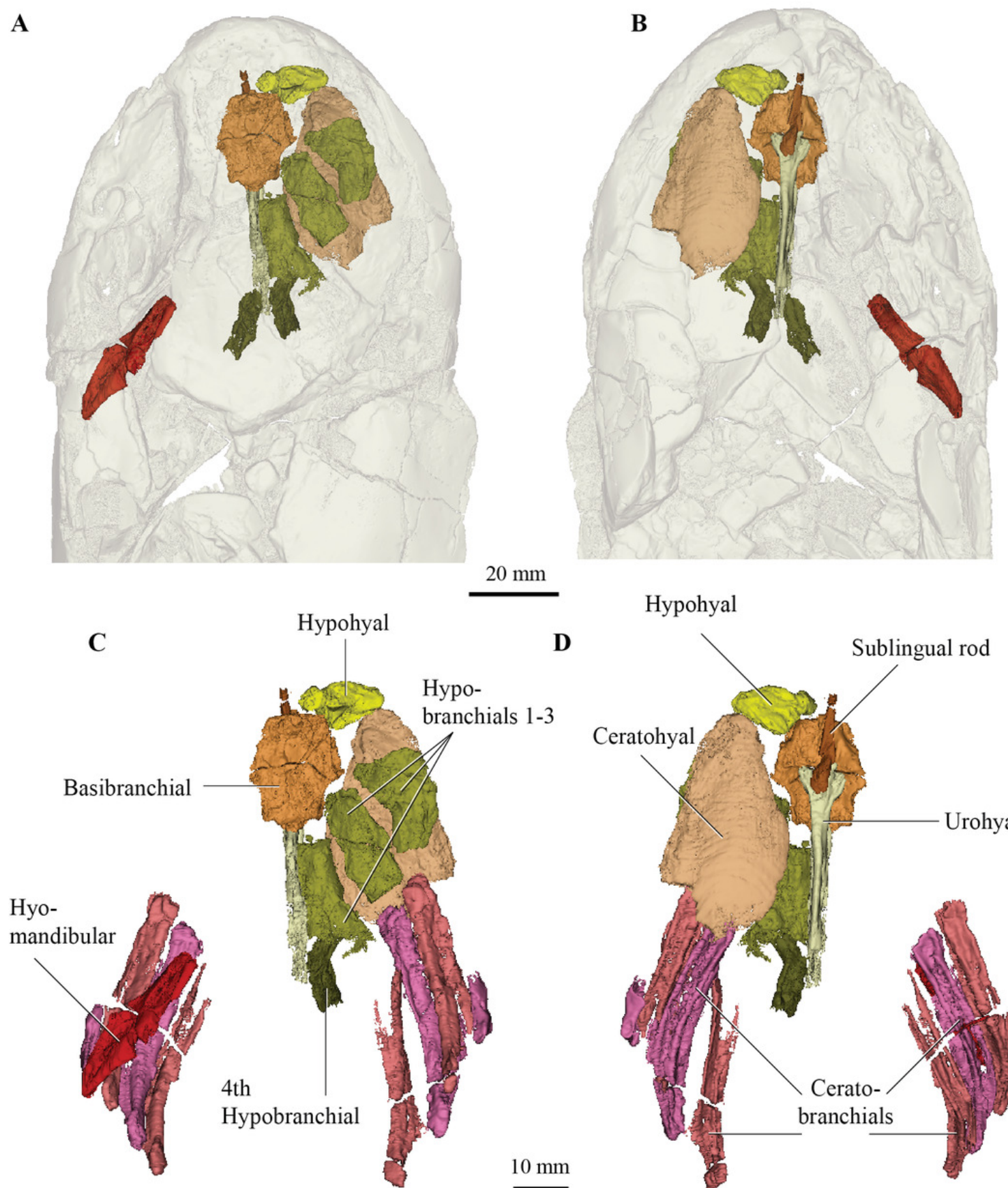

$20 \mathrm{~mm}$

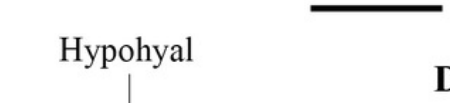

Hypohyal
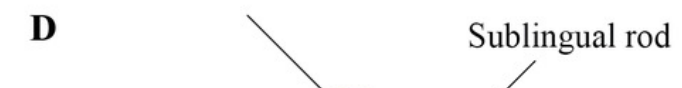

$10 \mathrm{~mm}$
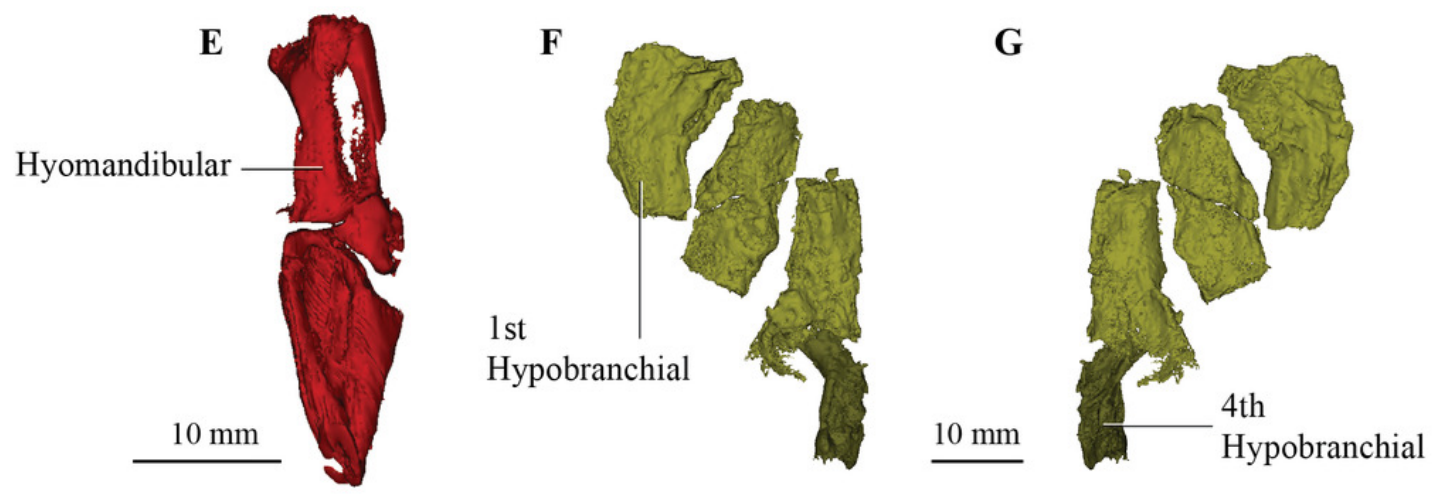


\section{Figure 5}

Figure 5. Micro-CT 3D rendering ( $58 \mu \mathrm{m}$ pixel size) of pectoral and axial elements of Cladarosymblema narrienense ( QMF 21082 ).

$A$, ventral view, and $B$, in dorsal view, showing placement of bones on holotype; pectoral girdle in C, dorsal view; and D, ventral view; E, F, anocleithra in alternate views; and neural arches in $\mathrm{G}$, lateral; I, dorsal; K, ventral view; ring centra in $\mathrm{H}$, lateral; J, dorsal; L, ventral view. 
A
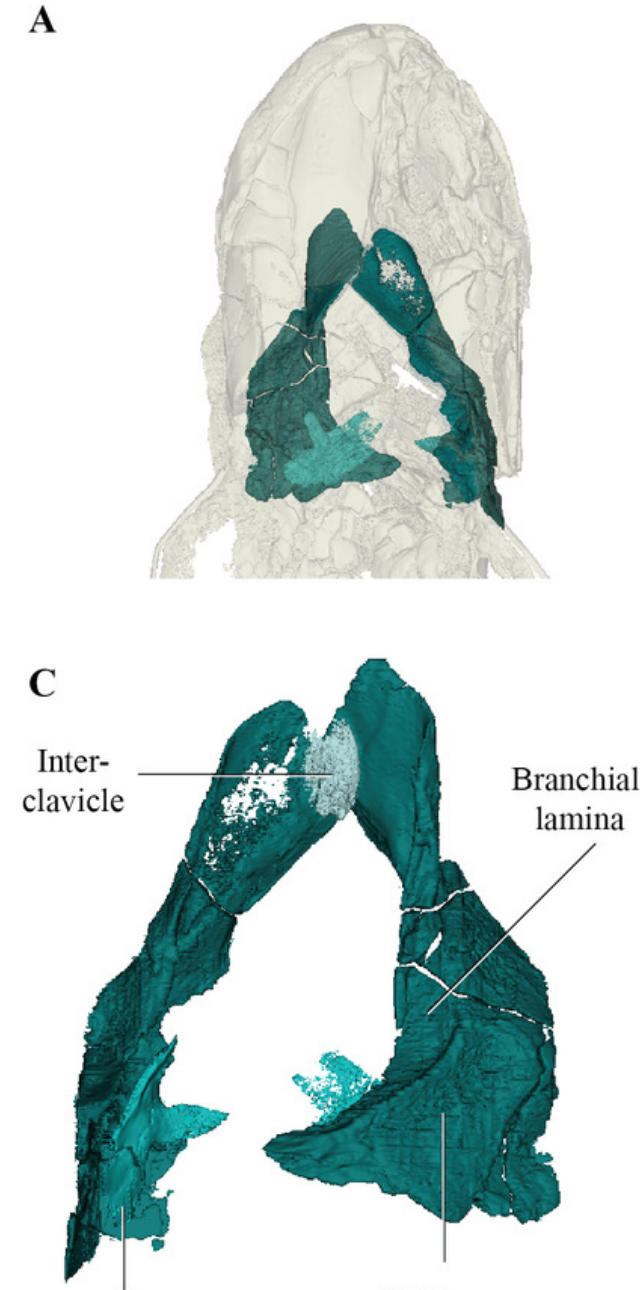

Anocleithrum

Cleithrum

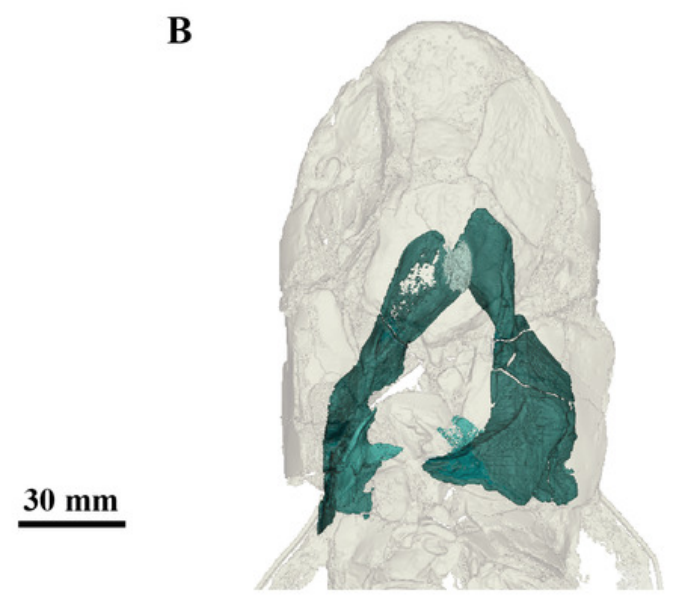

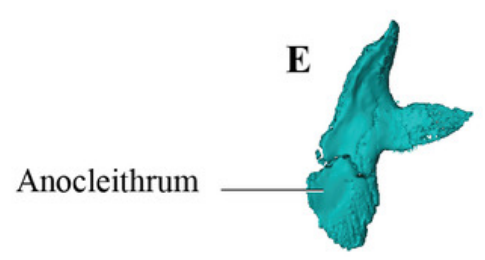

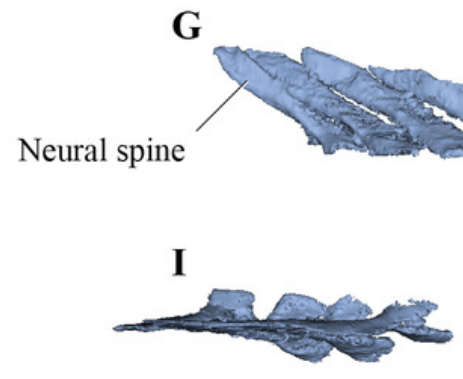

$\mathbf{K}$

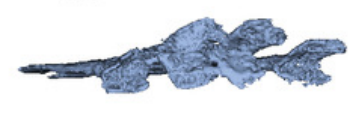

$10 \mathrm{~mm}$

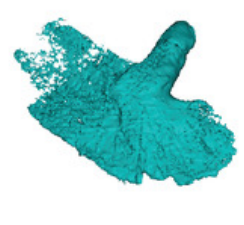

D

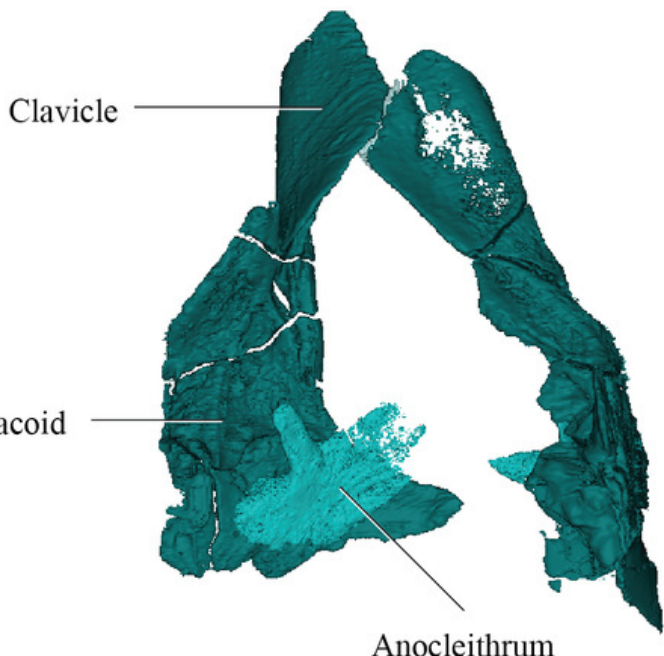

$20 \mathrm{~mm}$

Anocleithrum

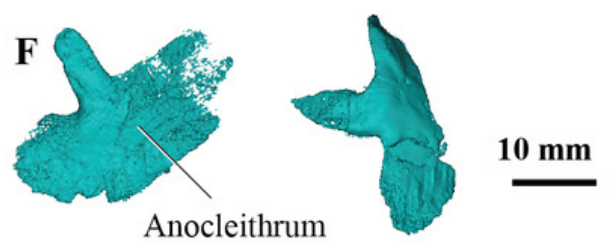

H
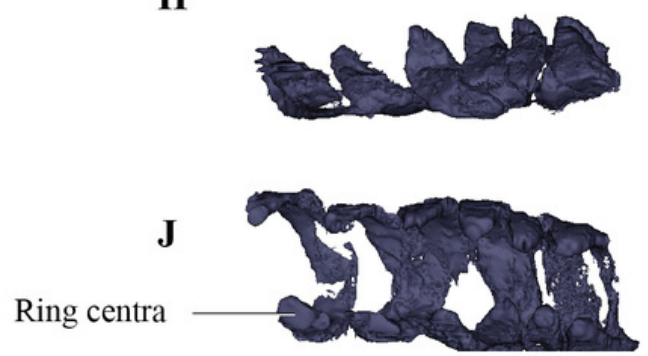

$\mathbf{L}$

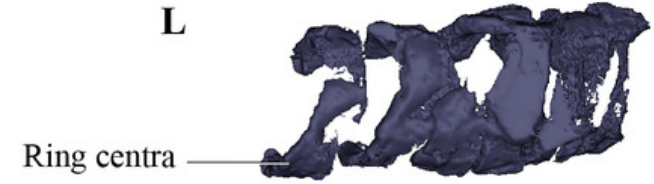

Ring centra 


\section{Figure 6}

Figure 6. Parsimony analyses.

A, 50\% majority-rule consensus tree from parsimony analysis with inclusion of all taxa showing monophyly of the Megalichthyidae; B, Canowindrid + Megalichthyid sub-set with most incomplete taxa excluded (Mahalalepis, M. mullisoni, M. laticeps, Sengoerichthys) provides greater resolution of megalichthyid phylogeny. Image silhouettes are authors own (elpistostegalid, rhizodont, megalichthyid, canowindrid) or from PhyloPic http://phylopic.org/ (Ichthyostega, Scott Hartman; Eusthenopteron \& Gogonasus, Michael Keesey). 
A

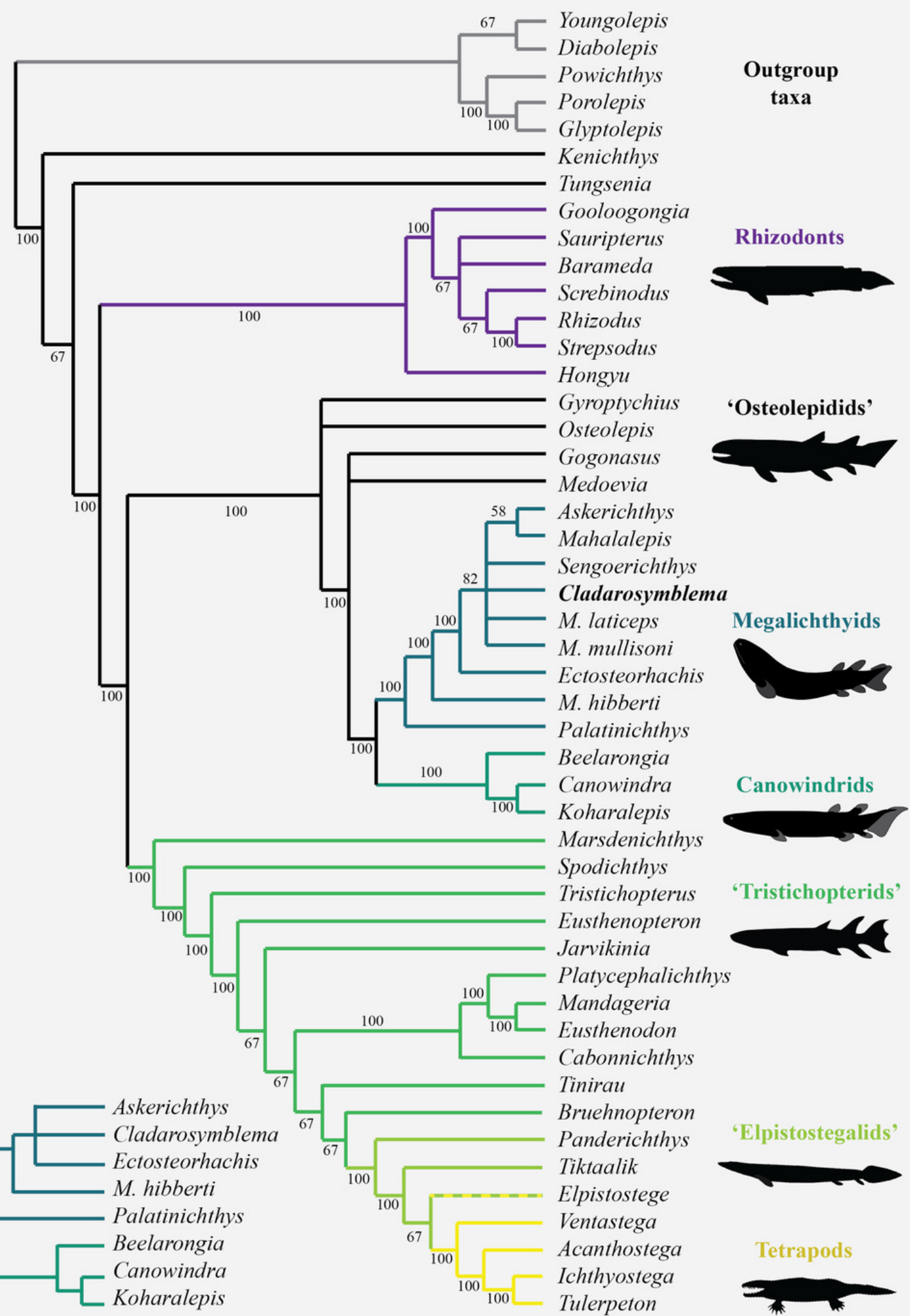




\section{Figure 7}

Figure 7. Cladarosymblema narrienense.

A, Lateral head reconstruction of Cladarosymblema narrienense, compiled from Fox et al. (1995) and new data. Colour-coded as follows: dermal skull roof (dark blue), cheek (light blue), lower jaw (pale green), opercular series (purple), and pectoral (dark green). Bones marked with "?" remain unknown in this taxon. B-E, micro-CT 3D rendering of all segmented bones in the holotype (QMF 21082): B, dorsal view; C, ventral view; D, anterolaterodorsal view; and $\mathrm{E}$, posteroventrolateral view. 

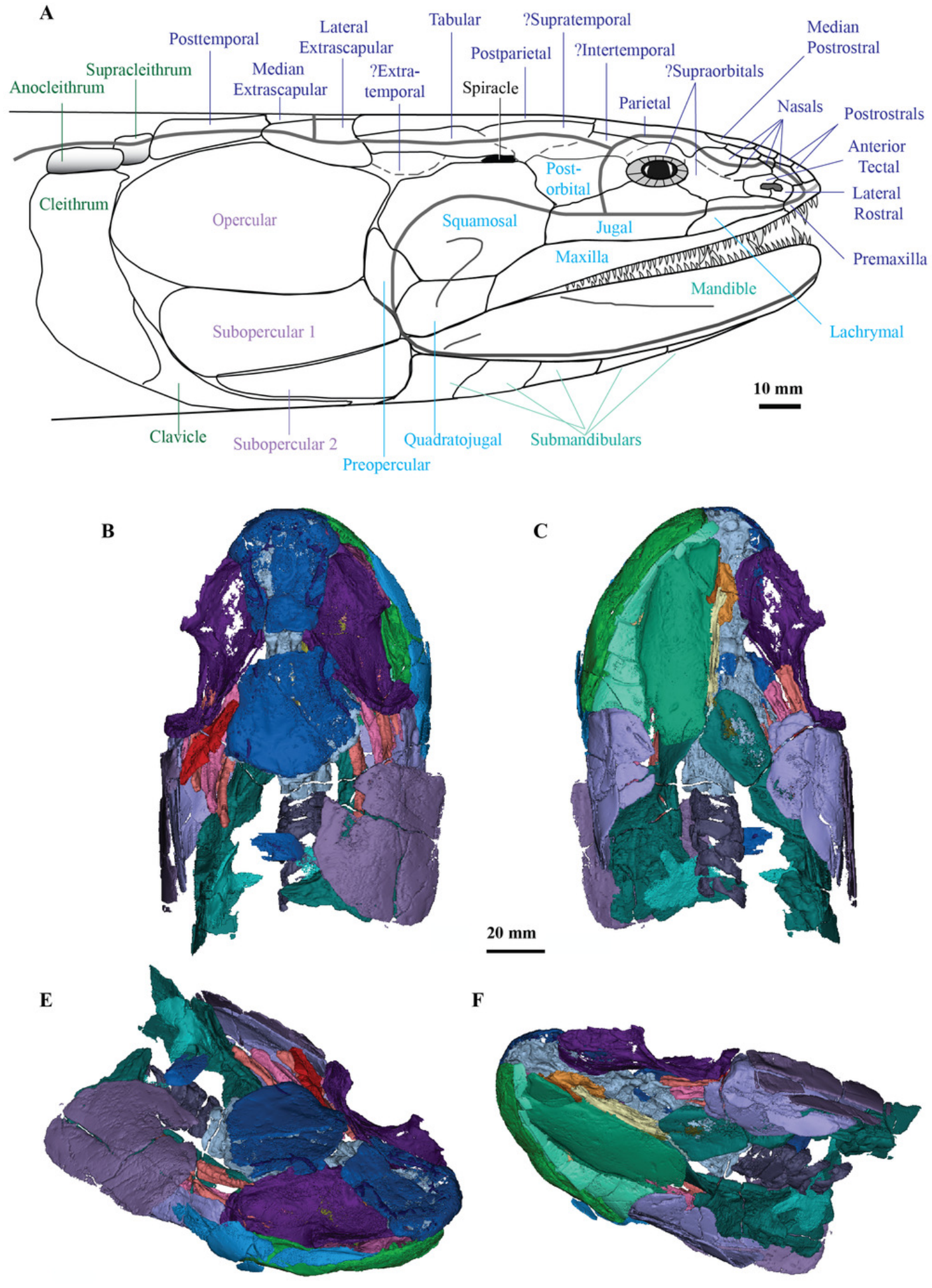